\title{
Measuring Public Attitudes towards the Police
} by Jonathan Jackson (the London School of Economics and Political Science) and
Ben Bradford (University College London)

Supplier Name: Jonathan Jackson (The London School of Economics and Political Science) Contract Number: 0D160-184515

Contract Value: $\$ 22,600$

Award Date: May 1, 2018

Delivery Date: July 2, 2018

Prepared for: Public Safety Canada

Contact: PS.CSCCBResearch-RechercheSSCRC.SP@canada.ca

Ce rapport est aussi disponible en français. 


\section{Author's Note:}

The views expressed are those of the authors and do not necessarily reflect those of Public Safety Canada. Correspondence concerning this report should be addressed to:

Research Division

Public Safety Canada

340 Laurier Avenue West

Ottawa, Ontario

K1A 0P8

Email: PS.CSCCBResearch-RechercheSSCRC.SP@canada.ca

\section{Product Information:}

(C) Her Majesty the Queen in Right of Canada, 2019

Cat. No.: PS18-43/2018E-PDF

ISBN Number: 978-0-660-28366-1

Related publications (registration number: POR 005-18):

Cat. No.: PS18-43/2018F-PDF (Final Report, French)

ISBN Number: 978-0-660-28367-8

This material may be freely reproduced for non-commercial purposes provided that the source is acknowledged.

\section{Political Neutrality Statement:}

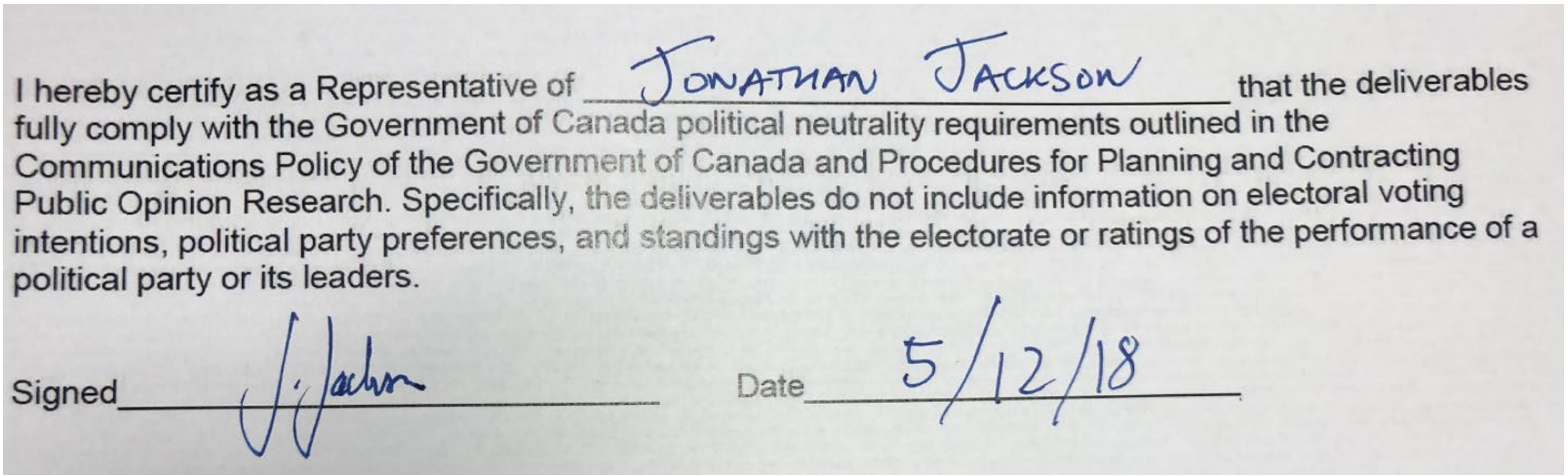




\section{Executive Summary}

Given that there is currently no common approach used across Canada to measure public attitudes towards the police, the objective of this study was to develop an empirically-informed small subset of items that can be used by Canadian police services for this purpose. We recommend a standardized, comprehensive and validated set of 12 'core' survey items to measure public attitudes towards the police. Police services across Canada can use them to capture public opinion in a way that is comparable between jurisdictions and track change over time. We also recommend a supplementary set of measures of socio-demographics, police-citizen contact, victimization experience, perceived safety and perceived disorder.

To identify our recommendations, we analysed data from an online survey of 2,527 Canadians - a quota sample of 500 Calgary area residents, 501 Ottawa area residents, 500 rural region residents, 526 Halifax Regional Municipality residents, and 500 French-speaking residents - that fielded 50 measures of public attitudes, experience and intentions. We used latent variable modelling to (1) assess measurement properties, (2) estimate the factors that predict public attitudes, (3) test a popular explanatory framework for understanding police-citizen relations (procedural justice theory), and (4) assess which measures work best on their own.

Our assessment of the measurement properties suggests that key constructs - procedural justice, engagement, distributive justice, effectiveness, legitimacy, and willingness to cooperate - are empirically distinct. It made little difference whether the survey was completed in French or in English. In both cases the indicators have good scaling properties.

Our analysis of the demographic predictors of the various different attitudes towards the police indicates three things. First, public attitudes were more positive among older people and among people with a relatively high income. Second, females perceived the police as more legitimate and were more willing to cooperate with the police, on average, than males. Third, people who identified primarily with being South Asian and Black tended to have more positive and more negative attitudes towards the police, respectively, than those who identified primarily with being White. Generally speaking, there was little difference between the expressed attitudes of self-identified White respondents and those who identified primarily with being Chinese or those who were grouped into the 'other' category.

Assessment of victim and perceived safety predictors showed that victims tended to be less positive about the police than non-victims (adjusting for other factors); that people who felt safe in their neighbourhood were more positive (on average) than people who did not feel safe; and that people who saw their neighbourhood as disorderly were less positive (on average) than people who saw their neighbourhood as orderly. The statistical effects of income shrank towards zero when victimisation, perceived safety and perceived disorder were included in the statistical models. This suggests that, compared to high-income individuals, low-income individuals are more likely to be victims, feel unsafe and perceive disorder around them and that it is this that accounts for the difference in views by income.

Procedural justice theory seems to work well in the current context. We found that procedural justice (treating people with respect and dignity, making decisions in fair, transparent and accountable ways, and allowing people voice) and legitimacy (right to power and authority to govern) explained a good deal of variation in people's willingness to cooperate with the police. Consistent with existing research from the United States (US), United Kingdom (UK) and Australia, this suggests that acting in procedurally just ways helps to generate the legitimacy that sustains and strengthens the ability of legal authorities to elicit public compliance and cooperation. There was, however, a novel finding in the current Canadian context. Bounded authority - the belief that the police respect the limits of their rightful authority - was less important in the current sample than it seems to be in the US and UK. What was more important was the belief that the police understand and respond to the needs of the local community. It seems, on this basis, that the police may be perceived as legitimate not only when they show that they wield their authority in fair and just ways, but also when they engage with the local community.

On the basis of our findings, we recommend the following 12 core survey items to measure attitudes towards the police:

\section{Procedural Justice}

- The police make decisions based on facts. 
- $\quad$ The police treat people with respect.

\section{Distributive Justice}

- The police provide the same quality of service to all citizens.

Community Engagement

- The police are dealing with the things that matter to people in this community.

Bounded Authority

- About how often would you say that the police in your neighbourhood exceed their authority?

\section{Effectiveness}

- Responding quickly to calls for assistance?

- Resolving crimes where violence is involved?

\section{Legitimacy}

- I feel a moral duty to follow police orders.

- I generally support how the police usually act.

Willingness to Cooperate

- I would help the police if asked.

Overall Trust and Confidence

- Taking everything into account, how good a job do you think the police in this area are doing?

- Taking everything into account, how good a job do you think the police in this country are doing?

Our findings of this project can be extrapolated to policy makers, researchers and police services that may use these questions on future surveys measuring attitudes towards the police in Canada. The contract value of this project is $\$ 22,600$. 


\section{Introduction}

Confidence, satisfaction, support, legitimacy, trust - people use a variety of different words to describe what in essence are public attitudes towards the criminal justice system. They sometimes use such terminology interchangeably. For example, the opening two sentences of a previous research summary report from Public Safety Canada:

"Promoting public confidence in the criminal justice system is seen as a valued goal of good government. Confidence and trust is needed to ensure the legitimacy of the justice system and the public's participation in the administration of justice (e.g., reporting crimes to the police, co-operating with criminal prosecutions)" (Public Safety Canada, 2004).

Regardless of what jargon is used, few doubt the importance of what the public thinks about the police. From a normative perspective, the public deserve a police service they believe they can trust to fulfil its various functions in an effective, fair and just way - in a way that takes into account (as much as possible) the interests of the individuals that the police 'serve and protect'. The public deserve a police service that is moral, just and appropriate - that has the legitimate right to exercise power and enforce the law. This is easier said than done. As a key 'first-responder' and the institution that deploys the state's monopoly on legitimate force, the police have a difficult balance to strike if they are to secure trust and legitimacy in the eyes of citizens.

From a practical perspective, police rely on active public support and cooperation. Most crimes come to the attention of the police when members of the public have reported them. Police rarely come across a criminal act while it is in commission, unless it is in response to a call from a citizen. Crimes go unsolved if victims and witnesses do not come forward with information to aid investigation. If the public do not trust the police, they are unlikely to cooperate in these ways, and if people do not believe that the police have the right to exercise power, they are unlikely to accept decisions and comply with officer orders.

It is important - even vital - that police organizations know what the people they serve and regulate think of them. Different tools can be used to assess public opinion, such as focus groups, deliberative polling, or 'big data'; however, representative sample surveys remain the most common and (arguably) the best tool because they generate robust estimates of the actual distribution of views across the population served by a particular police organization. Public Safety Canada (PS), in collaboration with the Halifax Regional Police Service (HRPS), aim to develop a standardized, comprehensive and validated set of 10-15 'core' survey items that can be used by police services across Canada to measure public attitudes towards the police in a way that is comparable between jurisdictions and within a given jurisdiction over time. We provide such a recommendation.

To make an evidence-based recommendation, we analyse data from a 10-minute online survey of 2,527 quota-sampled Canadians (500 Calgary area residents, 501 Ottawa area residents, 500 rural region residents, 526 Halifax Regional Municipality residents, and 500 French-speaking residents) that fielded 50 measures of the following constructs:

- Procedural justice

- Respecting the limits of rightful authority

- Distributive justice

- Community engagement

- Effectiveness

- Satisfaction and confidence

- Perceptions of crime, safety and disorder

- Legitimacy perceptions

- Willingness to cooperate

- Police contact and satisfaction with contact

- Previous victimization 
In this report, we assess the measurement properties of the measures and test the most popular explanatory framework - procedural justice theory (PJT). Our analysis has four stages:

1. We test the measurement properties of the indicators using confirmatory factor analysis (CFA). This is done in order to: (a) assess the extent to which indicators of the various constructs load onto one underlying factor (and thus can be treated as a psychometrically sound index), (b) assess the extent to which the various constructs are empirically distinct, and (c) test whether it matters whether the survey was completed in English or French;

2. We assess how public attitudes vary across key demographic groups (treating age, gender, income and ethnicity as predictors of the various constructs) and victimisation status, perceived safety and perceived disorder (adding these as further explanatory variables in the statistical models);

3. We test PJT using structural equation modelling (SEM) to estimate the various relationships between the different latent constructs; and

4. We focus on drawing out empirically-informed recommendations for the 10-15 'core' survey items. To do this, we use the CFA and SEM results as benchmarks for what we call 'substitutability analysis.' The goal is to gauge how well each single item can 'stand in' for the underlying latent variable (which is measured using multiple items).

Given that the 'substitutability analysis' is a key part of the study, it is worth at the outset explaining the process. We go looking for the single indicator that is best placed to stand in for the full set of measures. Consider an example where a strong positive relationship is found between procedural justice and legitimacy from an SEM using multiple indicators/items for each construct (e.g., the standardised regression coefficient is 0.50 ). We could then rerun the SEM, but this time use a single survey item to represent procedural justice. By cycling through each of the individual items included in the survey as measures of procedural justice, we could assess which single item comes closest to a standardised regression coefficient of 0.50 . Consider, also, that we find differences in procedural justice perceptions across ethnic groups. We could use the same procedure, cycling through each of the procedural justice indicators, to assess which single item gives the most similar ethnic group differences to the SEM findings.

Our recommendations for which single indicators to include in the 10-15 'core' survey items draw on these findings, taking into account conceptual issues where relevant. Criminologists typically define legitimacy along two lines (right to power judgements and felt obligation to obey), for instance, and distinguish, in the procedural justice concept, between interpersonal treatment, decision-making, voice-provision and trustworthy motives. Our recommendations are guided by such considerations. For instance, we recommend two legitimacy measures - one that captures a right to power judgement, the other that taps into obligation to obey.

The rest of the report is structured as follows: in the next section, we consider the concepts of trust and legitimacy, which pertain to many of the measures contained in the current survey of Canadians. ${ }^{1}$ We also review PJT. We then describe the methodology and present the findings, concluding with the recommendations for the 10-15 items.

\section{Conceptual Framework}

Social scientists routinely face the inconvenient fact that many concepts in their area of study are not directly measurable. For instance, political psychologists are often interested in political ideology; that is, the beliefs that people hold about the proper structure of society and the ways in which people and institutions ought to behave. Conservative and liberal ideologies, for example, serve as guidelines for particular forms of social judgement by shaping the value that people assign to groups, social practices and institutions. But political ideology is not something that they can get a direct (i.e., unmediated) handle on - for example, brain imaging technology cannot objectively measure a person's political ideology. So to measure political ideology, they ask individuals closed-ended questions and treat the

\footnotetext{
${ }^{1}$ Details of the data analysis can be found in Appendix A. The survey instrument can be found in Appendix B.
} 
answers given as indirect indicators of political ideology. This has the obvious implication that ideology can be defined and measured in a number of different ways and there is no objective benchmark to assess which one is 'correct.'

Trust and legitimacy are - like political ideology - unobservable psychological constructs. We do not (yet) have the technology to directly measure the extent to which an individual trusts police officers and sees the police as legitimate. So, like ideology, we look for indicators of the presence or absence of trust and legitimacy. When an individual reports in a survey situation that she has positive expectations about the fairness and effectiveness of police officers, for example, we infer that she trusts police officers to be fair and effective. When an individual says she feels a moral duty to obey the orders of police officers, we infer that she believes that the institution the officers embody is legitimate (i.e., she believes that the institution is entitled to exercise power, enforce the law and expect deference).

This means two things for the current discussion. First, trust and legitimacy can be defined in a number of different ways - there is no right or wrong answer to the questions 'what is trust?' and 'what is legitimacy?', for the simple reason that there is no objective criterion to assess the validity of any given definition. We thus need to set out the starting conceptual position before developing a clear set of measures. What do we mean by trust in the police and legitimacy? Do they have different components? Second, clear definitions are vital if we want to get a handle on how trust and legitimacy motivate behaviour. If, for instance, we want to understand how public contact with police shapes willingness to cooperate with officers in the future, then it is important to be clear about what trust and legitimacy are. If legitimacy is defined and measured solely as felt obligation to obey the police, then a positive correlation between legitimacy and cooperation would suggest that deference motivates proactive behaviour.

The past few years have seen a number of "conceptual stock-take" articles in the social science literature concerning what trust and legitimacy means in the context of the police and other legal authorities (e.g., Bottoms \& Tankebe, 2012; Hamm et al., 2017; Hawdon, 2008; Jackson, 2018; Jackson \& Gau, 2015; Tyler \& Jackson, 2013), and we refer the interested reader to those sources. Our goal in the following few pages is to explain the approach that we take to define trust and legitimacy. We start with our particular definition of trust. What do we mean by 'trust in the police'? Relatedly, on what bases do people judge the trustworthiness of the police? We then turn to legitimacy.

\section{What is Trust in the Police?}

There is a long history of measuring public trust (and confidence) in the police via surveys. In the UK, the first British Crime Survey in 1981 contained a question that has often been interpreted as a measure of trust and confidence: "Taking everything into account, how good a job do you think police in this area are doing?" In fact, this item has been fielded in every wave of the survey up to the present day. In the US, Gallup asked a question about the honesty and ethical standards of police in 1977, and a question about confidence in police for the first time in 1981 that became a series from 1993 onwards (Tuch \& Weitzer, 1997). Public debate about these and similar survey items is common, for example, in relation to an apparent decline in public trust in the UK from the 1980s to the 2000s (Bradford, 2011), or the racial 'gap' in trust in the US. Often missing from this debate and many criminological discussions of trust, however, was a clear understanding of the underlying concept. This lack of conceptual clarity impeded the development of a robust understanding of the nature, foundations and consequences of trust in police, especially because it was often not clear what, precisely, was under discussion. As noted above, words like trust, confidence, satisfaction, support and (less often) legitimacy were all used more or less interchangeably, and at least initially, this reflected a broader uncertainty in the academic literature on trust, wherein widely divergent concepts and definitions could be found. However, these have more recently begun to be resolved, and there is an emerging consensus around what, in a general sense, trust means.

On many current accounts, trust can be defined as the subjective judgement an individual makes about the likelihood that another person, organization, or other corporate body will follow through with an expected and valued action under conditions of uncertainty (Bauer, 2014; for variations on the theme, see Baier, 1986; Barber, 1983; Colquitt, Scott, \& LePine, 2007; Gambetta, 1988; Hardin, 2006; Mayer et al., 1995). Trust therefore requires that three elements be present: a trustor, a trustee, and some 
behaviour or outcome that the trustor wishes from the trustee. A series of important implications flows from this definition. First, trust is cognitive and subjective - the trustor must make a judgement about the trustee, which requires them to make inferences based on a range of sources (e.g., past experiences with trust in other contexts, personal ties with the trustee, a reading of their general behaviour, "gut feeling") when deciding the level of trust to place in the trustee. Second, trust constitutes (to some degree) a leap of faith. Because we do not know whether those we trust will actually do the things we trust them to do, to place trust implies a willingness to tolerate uncertainty (Möllering, 2001). When an action or event is guaranteed to occur, trust is irrelevant because the individual expecting it has zero probability of being disappointed. Third, trust only becomes a meaningful component of a relationship when the quantum of uncertainty generates risk for the trustor. Trust relationships revolve around actions or behaviours that are of value to the trustor. Actions or desired outcomes are beneficial, but failure to act or produce a desired outcome is in some sense harmful. Fourth and finally, for trust to form, the trustor must either disregard or voluntarily submit to the risk inherent in the probability judgement they have made (McEvily, 2011; Schilke \& Cook, 2013). Because the trustee may accidentally or deliberately fail to act or achieve an outcome, trust implies willing vulnerability to the potential misdeeds of the trustee.

Applied to the police, this definition of trust references people's expectations regarding valued future behaviours of officers under conditions of uncertainty. What will happen if officers are summoned to deal with an incident? Will they behave in an appropriate manner? Will they produce a desired outcome? These are questions that cannot be definitively answered, especially since human behaviour is inherently unpredictable. An individual can never be certain whether officers would turn up promptly if called, or whether those officers would behave appropriately once they arrived. But they may nevertheless form judgements about the intentions and capabilities of the officers to fulfil particular, valued functions, and these judgements will shape their willingness to accept vulnerability in relation to the police by behaving in ways that create risk for themselves - such as when, for example, they call police to report a crime or because they require assistance of some kind.

Relevant here is the distinction drawn in the criminological literature between effectiveness and fairness (a distinction that maps onto that drawn in the wider trust literature between outcomes and good intentions). At the heart of this distinction lies recognition that the police are expected to achieve a certain set of goals, behave in a particular way, and have appropriate intentions toward those they serve. On the one hand, they are tasked with achieving outcomes - catching criminals, responding quickly to emergencies, resolving conflicts, and so on - and trust judgements rest in part on assessments of how effective they are in achieving these goals. On the other hand, police are also expected to use their authority in measured, restrained, and professional ways: to be neutral when making decisions; respectful and fair when interacting with citizens; clear, open and honest in their communication; and provide citizens with a voice during interactions. There is much to suggest that this second requirement - evident in procedural justice, a subjective property of interactions between authorities and subordinates (Tyler, 1988, 1989, 1994) that concerns both interpersonal treatment and decision-making - may be a particularly important component of trust judgements. As an assessment of the processes used to make and enforce decisions or rules (Lind \& Tyler, 1988; Thibaut \& Walker, 1975) - and as a way of displaying appropriate and benevolent intentions - procedural justice has been shown to be more important than outcomes, effectiveness, and efficiency in the formation of trust, and consequently legitimacy, cooperation, and compliance (Sunshine \& Tyler, 2003; Tyler \& Huo, 2002 and see below).

Perhaps the "cleanest" measures of trust would therefore focus on an individual's expectations about how police officers would behave should they need to rely upon those officers' actions and behaviour in some way. This definition of trust has clarity, yet the vast majority of criminological research has adopted a slightly different conceptual and operational position. Survey respondents are typically not asked about their expectations regarding their own personal interactions with officers, but rather about how they think the police generally behave. This has alternately been called confidence (e.g., Cao, Frank, \& Cullen, 1996), satisfaction (e.g., Reisig \& Parks, 2000), and trust (e.g., Flexon, Lurigio, \& Greenleaf, 2009). Examples from these prior studies include:

- Agreement or disagreement with the statement that police treat citizens with respect (Reisig et al., 2007);

- How often do the police make fair and impartial decisions in the cases they deal with? (Tyler \& 
Jackson, 2014);

- When people call the police for help, how quickly do they respond? (Sunshine \& Tyler, 2003); and

- If a violent crime or house burglary were to occur near to where you live and the police were called, how slowly or quickly do you think they would arrive at the scene? (Hough et al., 2013).

Such questions reference expectations about the behaviour of the police as a collective actor; that is, the intentions and capabilities of officers and organizations in a general sense. While such judgements may correlate quite strongly with more specific expectations about how actual police officers would act if one were to come into future contact with them, they may also diverge under some important circumstances. For example, an individual might believe that the police would treat her fairly, but also believe that the police would treat different groups in her community differently (along, for example, the lines of ethnicity or class).

This approach fits well with the wider literature that proposes that trust can be best seen as a process, even though it adds complexity to the definition of trust by decoupling it from individual interaction. Trust 'begins' with evaluations of individual and/or organizational behaviour, which in turn form expectations of likely future behaviours. Evaluations and expectations shape, in turn, willing vulnerability under conditions of risk. One key implication of this processual account of trust is that the assessments people make, and the expectations they come to form, cannot relate solely to individual police officers but must draw on a much wider range of sources. While personal contact with police will be an important moment for trust formation (or attenuation), the range of potential predictors of trust is, indeed, very large - people draw on a disparate range of information to form their 'knowledge' of police. Research has shown, for example, that the character and condition of local social and physical environments are strong predictors of trust, perhaps most importantly because those living in orderly and socially cohesive neighbourhoods infer from that very order and cohesion that the police are both effective and well-intentioned (Jackson \& Bradford, 2009; Jackson et al., 2012).

This calls into question what we mean by 'police'. There have been attempts to distinguish between public perceptions of different types of police organizations and between different levels within the institutional framework of policing - to separate, for example, 'global' and 'specific' attitudes (Brandl et al., 1994). It might be surmised that trust, as described above, is more 'specific' in nature, because it is most clearly seen in moments when people make themselves vulnerable to the behaviour of particular officers. Moreover, people tend to distinguish between different 'types' and 'groups' of police. They can and do trust 'this' officer, but not 'that' one, or 'the police' as a whole. But it is likely more parsimonious to suggest that when people form expectations and evaluations, which are crystalized in acceptance of vulnerability in relation to specific officers, a police organization, or simply 'the police', they draw on perceptions and experiences that range across all three institutional levels. They infer the intentions of all police from the actions of the officer in front of them, and believe that particular officers (those that answer a call, for example) are trustworthy on the basis of a general sense that police are effective and well intentioned. This is not to claim that people do not distinguish between, for example, the trustworthiness of local and national police organizations, but rather that the way trust judgements are formed is likely to be complex, beyond the ability of a narrow range of survey items to capture, and thus largely beyond the scope of the current report. We therefore proceed on the basis that survey items that refer to a non-specific 'police' cover, at least to some extent, the range of meanings this word holds.

To summarise the discussion thus far, our position on the nature of trust is as follows:

1. Trust in the police is primarily cognitive and therefore subjective. One's willingness to be vulnerable is founded in the beliefs one has concerning the current and likely future behaviours of police officers, organizations and, often, a rather abstract notion of 'the police'. The 'knowledge' one has of the police may be garnered from many different sources.

2. Trust in the police is premised on beliefs that they are effective in the tasks set for them, behave in appropriate ways, and are well intentioned towards those they govern and serve.

3. Trust is based in part on direct and indirect experiences with police officers, particularly in relation to their abilities and (good) intentions. These are important moments in which the beliefs that constitute trust are formed. A necessary corollary is that there is significant overlap 
between trust - or distrust - in particular police officers (for example) and the institution of police, although these will not collapse into each other.

4. Trust also stems from many other diverse sources, including: generalized propensities and motivations to trust; the extent to which people believe police represent, enact and even embody values they share; and perceptions of crime, (dis)order, and cohesion.

\section{Components of Trust}

Trust could, then, be measured as 'willing vulnerability', which occurs at the end point of the trust process described above. In a recent paper Hamm et al. (2017) did exactly this. They fielded survey items such as "I am generally comfortable being vulnerable to the judgement of police in my community". While novel (albeit potentially overlapping with the authorization/deference aspect of the legitimacy concept), this approach has not yet established a firm foothold in the wider policing literature, and there is the possibility that such items look odd to many respondents, since the notion of vulnerability may not be the way people are used to thinking about policing. Another argument here is that since the end point of the trust process involves action - actually doing something that poses a risk along the lines described above - it is better captured by survey items that at least imply action. Yet, such items will only ever be an indication of trust, however they are phrased, due to the gap between what people say and what they do. In line with the mass of extant work, therefore, we focus here on evaluations and expectations of police when measuring trust (i.e., earlier in the trust process).

It follows from the discussion above that a range of such evaluations and expectations will form the trust judgements people make in relation to the police. In the current report we define trust in the police along a number of different dimensions, each of which are measured by asking people whether they think that the police generally act, for instance, in procedurally just ways. The first three dimensions relate to aspects of fairness. First, procedural justice refers primarily to how police interact with individuals on a one-to-one (or few-to-one, or one-to-few) basis. Central here is the quality of such interactions across the dimensions of procedural justice: neutrality, voice, respect, etc. What is primarily at stake here, therefore, is people's understandings of the way officers should behave, and their evaluations of the intentions of police.

Second, engagement with the community refers to the extent to which people believe police listen to, understand and act on the concerns of the communities they serve; and thus, again, speaks primarily to the intentions of police. This is in many ways a counterpart of procedural justice, implying a one (police organization) to many (community members) relationship founded in principles of open communication, voice and respect. It is important to note that while police do have relationships with communities that are distinct from their relationships with individuals, since community engagement is captured in surveys by interviewing individuals who are left free to judge what 'community' means, we should expect a strong correlation between these first two components of trust, particularly since respondents will infer 'community' views from their own.

Third, distributive justice relates primarily to the fairness of the outcomes police produce and the equity of their distribution across different groups in society. To put it another way, people ask themselves whether the benefits and impositions of policing are distributed in ways matched to underlying needs (e.g., victimisation) and behaviours (e.g., offending), or rather in ways premised on bias and/or discrimination toward particular groups. Distributive justice refers to the fair allocation of services, goods and so forth across aggregate groups in society - it thus has a different status to procedural justice, which can be both individual and aggregate. But, again, it is worth noting that distributive and procedural justices are likely to be highly correlated. On some accounts, perceptions of process fairness can be used as a way through which people judge outcome fairness (Lind \& Tyler, 1988; van den Bos et al., 1997), which of course requires that they are separate aspects of people's judgements. More broadly, however, and again stressing that we are dealing here with individual perception, these two factors often seem likely to be mutually constitutive. People may find it hard to imagine that an unfair outcome resulted from a fair procedure; symmetrically, it can be hard to believe that unfair processes produce fair outcomes.

The fourth component of trust is effectiveness. This component references the outcome related aspects of trust - the success of the police in securing the ends they are mandated to achieve. Another 
way of thinking about this component of trust is that it is more instrumental in character, as opposed to the more relational procedural justice and community engagement components. Again, though, there is likely to be a strong correlation with the other components, particularly since all are 'parts' of the overall trust construct.

The fifth component of trust is Respecting the limits of rightful authority. Recent work has argued that those subject to the power of the police desire that power to be exercised within certain boundaries and limits (Huq et al., 2017; Trinkner et al., 2018). There are places and situations where they do not wish the police to intrude, for example, and tools and tactics they think are inappropriate for police to use. When these boundaries are transgressed, people may question the legitimacy of the police in a way that transcends traditional concerns over procedural and distributive fairness.

\section{Overall Assessments of 'Trust and Confidence'}

In addition to the specific measures of trust and legitimacy outlined above (which are premised on a multi-dimensional concept of trust) there is a long - indeed longer - tradition of assessing overall 'trust and confidence' in police. The intention is often to provide a single 'headline measure' of public opinion, often reduced to a percentage (to give a hypothetical example - "in a recent survey, $65 \%$ of local residents said they had confidence in Anytown Police Department"). Survey items used in this way include:

- "Taking everything into account, how good a job do you think police in this area are doing" (Crime Survey of England and Wales or CSEW);

- "Please tell me on a score of 0-10 how much you personally trust ... the police" (European Social Survey); and

- "In the city or area where you live, do you have confidence in the local police force?" (Gallup World Poll).

Measures such as these have the benefit of simplicity: they are easily relatable to policy-makers and police leaders; they can provide important time-series data; and they also allow for a relatively clear distinction to be drawn between different types or levels of police. For example, a second CSEW item, similar to that above but referring to police 'in the country as a whole', was fielded for many years. However, because they require respondents to interpret key words and phrases - 'how good a job', 'trust', 'confidence' - they can be less useful when trying to probe the dynamics of public opinion (although one could, of course, explore the predictors of responses to such items). Notably, the current survey included two overall measures of trust and confidence.

\section{What is Police Legitimacy?}

While public trust has been a central organizing concept in the study of policing and public attitudes toward policing for many years, the question of legitimacy is a more recent addition to academic and policy debate. One reason for this may have been the social and political charge of the very word "legitimacy," with policy-makers, practitioners and, indeed, some academics possibly shying away from suggesting the police could be illegitimate. Yet, in the last decade or so, consideration of legitimacy as a social science concept and arguably the central defining aspect of police-public relations, has become firmly embedded in police research, policy and practice. In the UK, for example, Her Majesty's Inspectorate of Constabulary and Fire and Rescue Services' (HMICFRS) conducts annual inspections of police services in England and Wales, called PEEL (Police Effectiveness, Efficiency and Legitimacy) assessments. Launched in 2014, the "L" in PEEL stands for legitimacy, and police services are judged against a number of metrics (e.g., complaints data) that are intended to represent this aspect of their relationship with the communities they serve. As with trust, however, uptake of the term "legitimacy" has not necessarily been accompanied by a robust definition of what the term means.

At the most fundamental level, legitimacy concerns the justification of power (do we believe that those who govern us have the right to do so?) and the moral duty to obey (do we believe that those who govern us have the right to dictate appropriate behaviour?) (Coicaud, 2002: 10). Legitimacy is central to solving social coordination problems that involve the need for commitment from diverse groups with different values and conflicting interests, to nevertheless abide by and support centrally 
mandated solutions. The concept of legitimacy (the right of authorities to issue directives and the corresponding duty to follow those directives) encompasses public evaluations of power-holders and the notion of a 'properly established' relationship between, in this instance, police and public, with the idea that this relationship motivates the behaviour of the public in important ways.

Scholars concerned with police and other criminal justice institutions typically identify two aspects of, or constituent parts to, legitimacy judgements that map closely to this general schema. The first is the normative appropriateness of the institution. Do the public accept, or reject, the implicit and explicit claims that police make to be an institution that has the right to power? Framed around the idea of normative alignment, our approach assumes that appropriateness is judged against societal norms of conduct (e.g., do police behave in the way the police should behave?) and that people draw lessons from such judgements in relation to how they, as legal citizens, should correspondingly behave (e.g., should I report a crime to the police?). Procedural justice research consistently demonstrates that the most salient norms and values are those of fair process and just procedures. As noted above, the expectations people have of police commonly revolve around questions of respect, dignity, voice, neutrality, honesty and openness. Yet, other norms and values may also be important, including effectiveness, power applied within appropriate limits, and a wider set of concerns about the nature of order in society and the types of behaviours needed to assert it (Bradford \& Jackson, 2016; Huq et al., 2017; Jackson et al., 2012).

The second component of legitimacy is an internalized sense of consent to (properly established) authority structures. Duty to obey echoes the Weberian insight that power is transformed into authority when it is seen to be legitimate (Tyler, 2003, 2004). When one recognizes the authority of the police, one feels a normatively grounded obligation to obey officers' instructions and the rules and directives operative within the social and physical space governed by police (Tyler \& Jackson, 2013). Importantly, to be considered a component of legitimacy, 'duty to obey' should be characterised by truly free consent - the willed acceptance of rules and instructions. People could believe that they should accept the decisions made by police not because they are parties in a properly constituted relationship that places a set of duties upon them, but, for example, because they feel powerless to do otherwise or fear repercussions if they did not (Bottoms \& Tankebe, 2012; Johnson et al., 2014). Obeying instructions due to compulsion or fear does not indicate legitimacy. Implicit (and sometimes explicit - Huq et al., 2017; Van Damme, 2017) here is the idea that institutional normativity grants the right to dictate appropriate behaviour, at least in certain circumstances. Believing that the police are behaving in the 'right way' activates a sense that one has a duty to also act in the 'right way' and, for example, follow their instructions.

As with trust, it can sometimes be unclear where or to whom legitimacy is attached. On some accounts, individuals are trusted while roles are legitimate (Hawdon, 2008). Here, the 'office' of police confers legitimacy on the individual people who fill relevant roles, and legitimacy is primarily an institutional attribute. However, Weber's notion of charismatic authority makes it clear that individuals can invoke willing obedience, and even if legitimacy is an institutional attribute, the directives issued by police clearly come from individual people or specific police organizations, and are obeyed (or disobeyed) on that basis. As with trust, then, while we recognise the underlying complexity, we take the pragmatic approach that survey items referencing a generic, undefined, 'police' cover legitimacy at individual, organizational and institutional levels.

In summary, we take the view that there are three distinctive features of the empirical concept of legitimacy in the context of policing (and indeed other legal authorities):

1. Right to power: Citizens accept or reject the claim police make to rightfully hold power, based on some overarching judgement of the normative appropriateness of the institution;

2. Authority to govern: Citizens internalize a normatively grounded duty to obey the commands, rules, and laws connected to a justice institution that they believe is appropriate; and

3. Motivation: Legitimacy influences behaviour via strengthening positive and negative duties and obligations. Ascribing legitimacy to police strengthens the motivation to $(a)$ comply with the rules and orders that emanate from the institution and $(b)$ proactively cooperate with the goals of that institution (e.g., come forward to report crimes, provide information to the police, and give evidence in court).

Finally, we should note that the current survey fielded three measures of legitimacy: two capturing normative alignment and the third tapping into obligation to obey. In our own work we typically field 
multiple indicators of each of the two components of legitimacy and we generally find that they are empirically distinct and positively correlated (e.g., Bradford et al., 2014; Jackson et al., 2013). In the current study our hand was forced because of the limited number of legitimacy measures that were fielded.

\section{What is the Relationship between Trust and Legitimacy?}

Trust and legitimacy are plainly related to each other. Both revolve around normative concerns about the way police 'should' behave, and as aspects of people's relationships with police they have similar antecedents, most obviously perceptions/experiences of procedural justice. But does this mean they collapse into one another, forming a general 'attitude orientation' toward police? Empirical work suggests not (see below), making it important to conceptualize the relationship between the two.

One way to do this is to underline that trust involves evaluations and expectations regarding normatively appropriate behaviour. Hardin (2006: 17) argues that "to say we trust you means we believe you have the right intentions toward us and that you are competent to do what we trust you to do." If in a given context, people largely trust the police to be effective and fair, then it can be claimed that in some overall sense they believe police act in an appropriate manner. By contrast, legitimacy is the belief that an institution has the right to power and is entitled to be obeyed, and as a characteristic of the relationship between police and public, it emerges when the latter deem that the former tend to act in a proper manner. The principled justification of power that lies at the heart of legitimacy is therefore premised on judgements that police wield their power in normatively appropriate ways - that is, when the public trusts the police (Bradford et al., 2015; Jackson et al., 2012, 2013; Tyler \& Jackson, 2014). So we can suggest that trust flows into legitimacy (although, of course, legitimacy could influence how people make sense of police behaviour).

Consider also motivation. Thus far we have focused on trust and legitimacy as aspects of the relationship between police and public, premised on the judgements the latter make about the former. But their behavioural outcomes - the actions and activities they may or may not encourage and motivate among the public - are equally important. In the first instance, and as PytlikZillig and Kimbrough (2016) argue, there is a need to bracket off trust from involuntary and coerced actions and behaviours. Trust provides for "intrinsic motivation [that] comes from internal states and can still be affected by external forces, but...does not feel like one "should" or "must", do something" (PytlikZillig \& Kimbrough, 2016: 31). The actions motivated by trust - for example, to summon police and to cooperate with an investigation - must by definition be willing. If one acts in ways that are motivated by deterrence and threat of force, this is not trusting behaviour, because behaviour based on trust is premised on a set of positive expectations about how police will subsequently act. For instance, people will be more willing to report a burglary when they have some faith that officers will investigate, be professional, be fair, treat them respectfully, and so forth. When one has such positive expectations, one sees the point of calling police because one believes the call will be answered and that action will be taken, producing, in turn, 'positive goods'. These 'goods' need not be financial or even tangible researchers working with victims of crime, for example, have noted that the experience of respect and dignity in subsequent interactions with police can provide redress for the symbolic or social harm suffered as a result of victimisation.

Legitimacy, in contrast to trust, relates much more to power and the legal duties attached to citizenship. It brings in the notion of 'should', at least in as much as this concerns a positive sense of moral duty. When people believe that the police are moral, appropriate and proper, they believe that they, too, should act in normatively appropriate ways. Consider someone who is deciding whether or not to report a crime to the police. The belief that officers act in normatively appropriate ways may activate the corresponding civic sense that they, too, should act in normatively appropriate ways - one of which may be to assist the police, or at least make an effort to combat socially harmful behaviour. It may therefore be that both trust and legitimacy are, independently, predictors of people's willingness to engage in cooperative behaviour (like reporting a crime to the police). 


\section{Procedural Justice Theory: The Central Foundation of Trust and Legitimacy}

We can now start to put together the various building blocks. Procedural justice theory (PJT) is an increasingly popular theoretical approach through which to view police-community relations and, in particular, public trust and institutional legitimacy (e.g., Tyler, 1990, 2006, 2009; Tyler et al., 2015). With its central focus on the generation of consensual rather than coercive relationships, PJT resonates strongly with the ideology of policing by consent: it is premised on the idea that most people obey the criminal law most of the time because they think it is the 'right thing' to do so, and not simply because it is in their own best interests to do so. Core tenets of PJT - for example, the idea that 'fair' policing builds legitimacy and legitimacy enhances consent-based relationships between police and public - have become widely accepted among academics and policy-makers (e.g., President's Task Force on 21st Century Policing, 2015).

PJT makes four main predictions:

1. that it is the style of social interaction and the neutrality of decision-making in encounters between individuals and justice officials that are crucial in shaping behaviour;

2. that the social bonds between individuals and institutions are strengthened when authorities make fair and neutral decisions, and when people are treated in ways that are recognised to be fair, respectful and legal - and not based on bias and stereotypes;

3. that out of these social bonds comes a sense that legal authorities are legitimate - that the police and courts have the right to power, the right to dictate appropriate behaviour, and are morally justified in expecting cooperation and compliance; and

4. that legitimacy promotes normative modes of compliance and cooperation that are both more stable and more sustainable in the long run than models of policy based on deterrence, sanction and fear of punishment.

Within this framework, the vast majority of prior PJT research has focused on four particular areas of concern: a) the aspects of police behaviour that individuals place most importance upon when interacting with officers; b) the dimensions on which people trust or do not trust the police; c) how various trustworthiness judgements relate to judgements about the legitimacy of the police; and/or d) how fairness perceptions and legitimacy judgements relate to behavioural intentions to comply with the law, cooperate with the police and other outcomes. This trajectory of research reflects the fact that the primary concern to date has been the validity of some of PJT's central contentions. There can be little dispute that this work has done a good deal to validate some of the theory's core hypotheses, although more research is needed.

Key aspects of PJT can be tested with the current data. Figure 1 provides an overview of the framework, linking (i) people's contact with the police (police-initiated and citizen-initiated) to (ii) whether they trust the police to engage with the community and act in fair, effective and lawful ways, to (iii) whether they view the police as legitimate holders of power, to (iv) their willingness to cooperate with officers. Modelling the data according to this framework allows us to further validate key constructs by exploring the extent to which correlations between them correspond to existing studies and helps to identify the 'core' indicators (see below). We also note that including cooperation in the analysis provides for a tangible outcome of trust and legitimacy, which may serve to make these concepts both more 'real' and more relevant for policy-makers and others using survey data. 
Figure 1. An overview of PJT

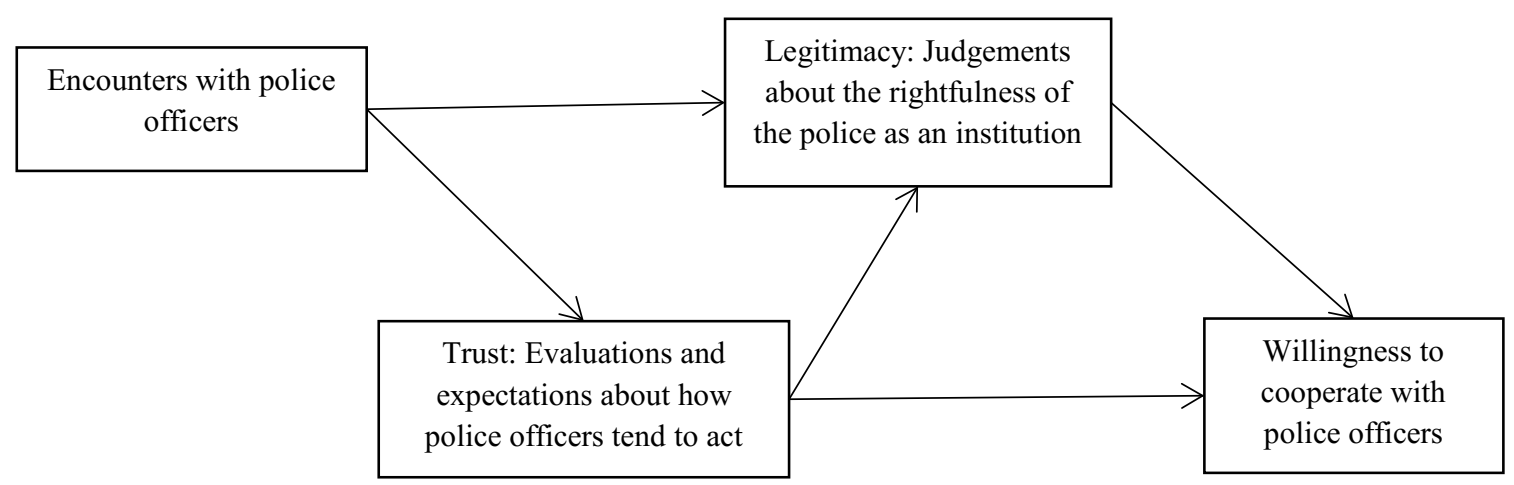

The conceptual discussion above has outlined a number of constructs we believe are central to defining the relationship between police and public, at least as this is experienced from the subjective position of the latter, and which should therefore be represented in the core set of indicators. These are:

- Trust, as evaluations and expectations of

- procedural justice

- community engagement

- distributive justice

- effectiveness

- respect for boundaries

- Legitimacy, as value judgements in the form of

- normative alignment with police

- moral duty to obey police

- Cooperation, as a readiness to help, support and work with police

\section{Methodology}

The data used for this project were not collected by the authors; rather, the data were collected by Corporate Research Associates in a survey exercise led by Halifax Regional Police with support from Calgary Police Service and Ottawa Police Service. Between January 10 and 22, 2018, data were collected using online survey panels, targeting a minimum of 500 respondents from each of the following groups: Halifax Regional Municipality residents, Calgary area residents, Ottawa area residents, residents from rural areas across Canada, and those indicating that French is their first language. The final sample size for this survey was 2,527 . The demographic questions were presented to respondents at the outset of the survey. These were followed by the attitudinal questions, which were randomized by theme and within each theme to control for potential order effects (see survey instrument in Appendix B).

\section{Measures}

The survey fielded the following measures:

Procedural justice (disagree/agree, 5-point scale)

- The police treat people fairly.

- The police treat people with respect.

- The police make decisions based on facts.

- The police respect people's rights. 
- The police address citizens in a respectful manner and appropriate tone.

- The police show care and concern for the welfare of the citizens they deal with.

- The police know how to carry out their official duties properly.

- The police treat you with respect if you had contact with them for any reason.

- The police explain their decisions to the people they deal with.

- The [police service] is an organization with integrity.

- The [police service] is an open and transparent organization.

- About how often would you say that the police in your neighbourhood make fair, impartial decisions in the cases they deal with?

Distributive justice (disagree/agree, 5-point scale)

- The police treat everyone fairly, regardless of who they are.

- The police treat everyone equally.

- The police provide the same quality of service to all citizens.

- The police enforce the law consistently when dealing with people.

Engagement (disagree/agree, 5-point scale)

- The police understand the issues that affect this community.

- The police are dealing with the things that matter to people in this community.

- The police can be relied on to be there when you need them.

- The police are sensitive to the needs of different cultures.

Effectiveness (disagree/agree, 5-point scale)

- In general, to what extent do you agree that the [police service] [is/are] effective at resolving crimes where violence is involved?

- In general, to what extent do you agree that the [police service] [is/are] effective at resolving property crimes, such as theft?

- In general, to what extent do you agree that the [police service] [is/are] effective at responding quickly to calls for assistance?

Bounded authority (disagree/agree, 5-point scale)

- About how often would you say that the police in your neighbourhood exceed their authority?

Legitimacy (never/always, 5-point scale)

- The police generally have the same sense of right and wrong as I do.

- I generally support how the police usually act.

- I feel a moral duty to follow police orders.

Cooperation (disagree/agree, 5-point scale)

- I would help the police if asked.

- I would call the police for assistance.

- I would call the police to report a crime.

- I would report suspicious activities to police.

- I would help the police by giving evidence in court.

Police-initiated contact (yes/no and dissatisfied/satisfied, 5-point scale)

- In the past 2 years, did the police approach you, stop you or make contact with you for any reason?

- How dissatisfied or satisfied were you with the way the police treated you the last time this happened? 


\section{Citizen-initiated contact (yes/no and dissatisfied/satisfied, 5-point scale)}

- In the past 2 years, have you approached or contacted the police for any reason?

- How dissatisfied or satisfied were you with the way the police treated you the last time this happened?

Confidence in the police (very poor/excellent, 5-point scale)

- Taking everything into account, how good a job do you think the police in this area are doing?

- Taking everything into account, how good a job do you think the police in this country are doing?

Victimisation (yes/no)

- In the past two years, have you been a victim of any crime?

Perceived safety (dissatisfied/satisfied, 5-point scale)

- In general, how satisfied are you with your personal safety from crime?

Perceived disorder (not a problem/big problem, 5-point scale)

In your neighbourhood, how much of a problem are ...

- Noisy neighbours or loud parties?

- People hanging around on the streets?

- Garbage or litter lying around?

- Vandalism, graffiti and other deliberate damage to property or vehicles?

- People being attacked or harassed because of their skin colour, ethnic origin or religion?

- People using or dealing drugs?

- People being drunk or rowdy in public places?

\section{Scaling}

\section{Findings}

The first step of analysis used confirmatory factor analysis (CFA) to assess the scaling properties of the measures of the constructs that were operationalised using multiple indicators (procedural justice, distributive justice, engagement, effectiveness, legitimacy and cooperation). One response to our conceptual discussion (above) might be to assume a priori that trust is one 'thing', albeit made up of five sub-components (as with legitimacy, albeit with two sub-components). We take a different approach. We make it an empirical question whether the components of trust collapse into one another, or whether they instead represent distinct aspects of individuals' perceptions and understandings of police - do people make separate assessments about fairness and effectiveness, for example?

In line with this, we take a reflective approach to measurement. We assume that various aspects of trust, legitimacy etc. are unobservable psychological constructs, the presence of which can be inferred by the effect they exert on what we can observe (in this case the way those surveyed responded to the questions with which they were presented). We treat the measures as imperfect indicators of the underlying concept that are subject to measurement error; we assume: (a) that the correlations between the measures are by virtue of them measuring the same underlying concept of interest and (b) that the variance that is not shared is measurement error. Note that we do not take a strong position on causality, specifically the idea that the latent construct is causing variation in the various indicators. This means that we are relatively relaxed about the possibility that including other variables in the fitted models (e.g., socio-demographic indicators) could affect the parameter estimates.

Results from a series of fitted CFA models using MPlus 7.2 are shown in Table 1 (indicators were set as categorical and all latent constructs were allowed to covary). Each model also includes the single indicator of bounded authority, set to be correlated with the latent variables. The exact and approximate fit statistics suggest that the six-factor (M1) and the various five-factor models (M2a-M2d) fit the data adequately, at least according to the approximate fit statistics, where one typically looks for CFI $>.95$; TLI $>.95$; RMSEA $<.08$ (see Hu \& Bentler, 1999). The four factor model - that combines 
procedural justice, distributive justice and engagement (M3) - has a relatively poor approximate fit, at least when judged on the basis of RMSEA.

Table 1. Fit statistics for fitted CFA models

\begin{tabular}{|l|l|c|c|c|c|c|c|c|}
\hline Model & Chi-Square & $\mathrm{df}$ & $p$ & RMSEA & $\begin{array}{c}\text { RMSEA } \\
90 \% \text { CI }\end{array}$ & CFI & TLI \\
\hline M1 & Six-factors & 5,782 & 444 & $<.0005$ & .069 & $.067 ; .071$ & .981 & .979 \\
\hline M2a & $\begin{array}{l}\text { Five-factors (combining procedural } \\
\text { justice and legitimacy) }\end{array}$ & 7,768 & 450 & $<.0005$ & .080 & $.079 ; .082$ & .975 & .972 \\
\hline M2b & $\begin{array}{l}\text { Five-factors (combining procedural } \\
\text { justice and engagement) }\end{array}$ & 7,428 & 450 & $<.0005$ & .078 & $.077 ; .080$ & .976 & .973 \\
\hline M2c & $\begin{array}{l}\text { Five-factors (combining procedural } \\
\text { justice and distributive justice) }\end{array}$ & 11,356 & 450 & $<.0005$ & .098 & $.096 ; .099$ & .962 & .958 \\
\hline M2d & $\begin{array}{l}\text { Five-factors (combining engagement } \\
\text { and effectiveness) }\end{array}$ & 6,568 & 450 & $<.0005$ & .073 & $.072 ; .075$ & .979 & .977 \\
\hline M3 & $\begin{array}{l}\text { Four-factors (combining procedural } \\
\text { justice, distributive justice and } \\
\text { engagement) }\end{array}$ & 13,177 & 455 & $<.0005$ & .105 & $.104 ; .107$ & .956 & .952 \\
\hline
\end{tabular}

We take the view that the six-factor model is marginally better, although it is important to point out there is an extremely strong overlap between procedural justice, distributive justice, community engagement, and legitimacy (c.f. Jackson et al., 2012; Jackson \& Kuha, 2016). We should also point out that, in the six-factor model, factor loadings and $\mathrm{R}^{2} \mathrm{~s}$ are all relatively high, indicating good scaling properties. All standardized factor loadings are provided in Appendix A. For procedural justice, the standardized factor loadings range from .66 to .93 , and the $\mathrm{R}^{2} \mathrm{~s}$ range from .43 to .87 . For engagement, the standardized factor loadings range from .85 to .87 , and the $\mathrm{R}^{2} \mathrm{~s}$ range from .72 to .76 . For distributive justice, the standardized factor loadings range from .92 to .96 , and the $\mathrm{R}^{2} \mathrm{~s}$ range from .85 to .93 . For effectiveness, the standardized factor loadings range from .72 to .84 , and the $\mathrm{R}^{2} \mathrm{~s}$ range from .52 to .70 . For legitimacy, the standardized factor loadings range from .72 to .92 , and the $\mathrm{R}^{2} \mathrm{~s}$ range from .52 to .85 . For willingness to cooperate, the standardized factor loadings range from .83 to .92 , and the $\mathrm{R}^{2} \mathrm{~s}$ range from .69 to .85 .

Table 2 presents correlations between the latent variables estimated within the six-factor CFA model (including, in addition, the single indicator of bounded authority). We see especially strong bivariate associations between: (a) procedural justice and engagement $(r=.90)$; (b) procedural justice and distributive justice $(r=.88)$; (c) procedural justice and legitimacy $(r=.88)$; (d) engagement and legitimacy $(r=.85)$; (e) engagement and distributive justice $(r=.84)$; and (f) engagement and effectiveness $(r=.84)$.

Table 2. Correlations between latent constructs from the six factor CFA model (plus the single indicator of bounded authority)

\begin{tabular}{|l|c|c|c|c|c|c|c|}
\hline & 1 & 2 & 3 & 4 & 5 & 6 & 7 \\
\hline 1. Bounded authority & - & & & & & & \\
\hline 2. Procedural justice & $.51^{* * *}$ & - & & & & & \\
\hline 3. Engagement & $.43^{* * *}$ & $.90^{* * *}$ & - & & & & \\
\hline 4. Distributive justice & $.44^{* * *}$ & $.88^{* * *}$ & $.84 * * *$ & - & & & \\
\hline 5. Effectiveness & $.35^{* * *}$ & $.77^{* * *}$ & $.84 * * *$ & $.68^{* * *}$ & - & & \\
\hline 6. Legitimacy & $.51^{* * *}$ & $.88^{* * *}$ & $.85^{* * *}$ & $.78^{* * *}$ & $.71^{* * *}$ & - & \\
\hline $7 . \quad$ Willingness to cooperate & $.36^{* * *}$ & $.62 * * *$ & $.65^{* * *}$ & $.49^{* * *}$ & $.54 * * *$ & $.73^{* * *}$ & - \\
\hline
\end{tabular}

To assess the impact of the language of the survey, we fitted the six-factor CFA model for people who completed the survey in English and for people completed the survey in French. The fit was good for both (English: RMSEA .072 [90\% CI .070, .073], CFI .982, TLI .979; French: RMSEA .064 
[90\% CI .061, .067], CFI .982, TLI .979). We also tested the model for respondents living in an urban area and respondents living in a rural area separately, finding again that the fit was good for both (urban: RMSEA .071 [90\% CI .069, .073], CFI .980, TLI .977; rural: RMSEA .063 [90\% CI .059, .067], CFI .987, TLI .985). This, combined with similar standardized factor loadings (see Appendix A), indicates that it mattered little whether the survey was completed in English or French or whether the respondents resided in urban versus rural areas across Canada.

\section{Predictors of Public Attitudes}

To find out whether trust, legitimacy and cooperation varied between key social groups, we regressed each of the six latent constructs (procedural justice, engagement, distributive justice, effectiveness, legitimacy, and willingness to cooperate) onto age, gender, income, ethnicity, French vs. English language (in terms of filling in the survey), and rural vs. urban. We also regressed bounded authority (as a single indicator) onto the same demographic characteristics. Table 3 summarises the results. Note that Table 3 displays partial associations (e.g., the observed association between age and procedural justice controls for the roles that gender, income, ethnicity, survey language and urban/rural variously play). Data come from a cross-sectional survey, so we are engaging in descriptive not causal inference. Note also that gender, ethnicity, language and type of area are all dummy variables with the following reference categories: male, white, English language and urban.

We find consistent positive statistical effects in terms of age - the older people are, the more positive they are about the police. A similar pattern is found with income - the more people earn, the more positive they are about every aspect of police behaviour, except police effectiveness (no statistically significant association was found). Gender effects were only found for legitimacy and cooperation - females tend to, on average, invest more legitimacy in the police than males, and be more willing to cooperate with the police compared to males. In terms of ethnicity ${ }^{2}$, compared to people who identified primarily with being White, people who identified primarily with being South Asian and Black tended to have more positive and more negative attitudes towards the police, respectively. Generally speaking, little difference was found between the expressed attitudes of people who identified primarily with being White versus Chinese or those grouped into the 'other' category. Respondents who completed the survey in French tended to report higher levels of fairness (procedural justice, distributive justice and bounded authority) and effectiveness than respondents who completed the survey in English. Finally, people living in rural areas tended to see the police as slightly less effective compared to people living in urban areas.

\footnotetext{
${ }^{2}$ Respondents were asked about the racial or cultural group(s) they belong to. The majority self-identified as White $(n=2,214$, $88 \%)$. Smaller numbers self-identified as South Asian $(n=44,2 \%)$, Chinese $(n=62,2.5 \%)$ and Black $(n=48,2 \%)$. The numbers of people in each of the other groups (e.g., 28 First Nations, 28 Arabs, 25 Latin Americans and 10 Southeast Asians) were too small for analysis, so we constructed an 'other' category $(n=159,6 \%)$.
} 

$\begin{array}{ll}\text { Public Safety } & \text { Sécurité publique } \\ \text { Canada } & \text { Canada }\end{array}$

Table 3. Demographic predictors of public attitudes towards the police

\begin{tabular}{|l|c|c|c|c|c|c|c|c|c|}
\hline & Age & Female & Income & South Asian & Chinese & Black & Other & French & Rural \\
\hline Procedural justice & $0.007^{* * *}$ & 0.049 & $0.048^{* * *}$ & $0.507^{* * *}$ & -0.035 & $-0.437^{* * *}$ & -0.045 & $0.149^{* * *}$ & 0.042 \\
\hline Distributive justice & $0.005^{* * *}$ & -0.003 & $0.035^{* *}$ & $0.684^{* * *}$ & 0.184 & $-0.325^{*}$ & -0.004 & $0.165^{* * *}$ & 0.092 \\
\hline Engagement & $0.007 * * *$ & 0.071 & $0.055^{* * *}$ & $0.591^{* * *}$ & -0.029 & $-0.476^{* *}$ & -0.066 & -0.065 & -0.001 \\
\hline Effectiveness & $0.004^{* *}$ & 0.069 & -0.001 & $0.347^{*}$ & -0.142 & -0.207 & -0.044 & $0.103^{*}$ & $-0.122^{*}$ \\
\hline Bounded authority & $0.010^{* * *}$ & -0.006 & $0.070^{* * *}$ & -0.116 & -0.151 & -0.241 & -0.087 & $0.217^{* * *}$ & 0.021 \\
\hline Legitimacy & $0.009^{* * *}$ & $0.125^{* *}$ & $0.063^{* * *}$ & $0.490^{* * *}$ & -0.118 & $-0.431^{* * *}$ & -0.159 & 0.079 & -0.016 \\
\hline Cooperation & $0.013^{* * *}$ & $0.226^{* * *}$ & $0.096^{* * *}$ & $0.363^{*}$ & $-0.405^{* *}$ & $-0.335^{*}$ & -0.136 & 0.002 & -0.016 \\
\hline$* p<0.05, * * p<0.01, * * * p<0.001$ & & & & & & & &
\end{tabular}

Table 4. Demographic, victimisation, perceived safety and disorder predictors of public attitudes towards the police

\begin{tabular}{|l|c|c|c|c|c|c|c|c|c|c|c|c|}
\hline & Age & Female & Income & South Asian & Chinese & Black & Other & French & Rural & Victim & Perceived safety & Perceived disorder \\
\hline Procedural justice & $0.005^{* * *}$ & 0.074 & 0.019 & $0.518^{* * *}$ & 0.000 & $-0.539^{* * *}$ & 0.001 & $0.131^{* *}$ & 0.049 & $-0.122^{*}$ & $0.468^{* * *}$ & $-0.077^{* * *}$ \\
\hline Distributive justice & $0.003^{*}$ & 0.022 & 0.008 & $0.677^{* * *}$ & 0.217 & $-0.377^{*}$ & 0.046 & $0.142^{* *}$ & 0.085 & $-0.167^{* *}$ & $0.360^{* * *}$ & $-0.077^{* * *}$ \\
\hline Engagement & $0.006^{* * *}$ & $0.102^{*}$ & $0.027^{*}$ & $0.613^{* * *}$ & 0.012 & $-0.544^{* * *}$ & -0.012 & 0.042 & 0.008 & $-0.137^{*}$ & $0.492^{* * *}$ & $-0.048^{*}$ \\
\hline Effectiveness & 0.003 & $0.088^{*}$ & $-0.033^{*}$ & $0.331^{*}$ & -0.122 & -0.290 & -0.007 & 0.073 & $-0.128^{*}$ & $-0.151^{* *}$ & $0.463^{* * *}$ & $-0.058^{* *}$ \\
\hline Bounded authority & $0.007^{* * *}$ & 0.019 & $0.038^{* *}$ & -0.114 & -0.124 & -0.308 & -0.012 & $0.174^{* * *}$ & 0.023 & $-0.131^{*}$ & $0.260^{* * *}$ & $-0.234^{* * *}$ \\
\hline Legitimacy & $0.008^{* * *}$ & $0.138^{* * *}$ & $0.038^{* * *}$ & $0.484^{* * *}$ & -0.093 & $-0.514^{* * *}$ & -0.122 & 0.054 & -0.010 & $-0.109^{*}$ & $0.382^{* * *}$ & $-0.069^{* *}$ \\
\hline Cooperation & $0.012^{* * *}$ & $0.231^{* * *}$ & $0.076^{* * *}$ & $0.334^{*}$ & $-0.399^{* *}$ & $-0.388^{* *}$ & -0.107 & -0.033 & -0.015 & -0.107 & $0.282^{* * *}$ & -0.040 \\
\hline
\end{tabular}

${ }^{*} p<0.05, * * p<0.01, * * * p<0.001$ 
We then added three factors (victimization experience, perceived safety and perceived disorder) to the various SEM models. As before, we regressed the six latent constructs (procedural justice, engagement, distributive justice, effectiveness, legitimacy, and willingness to cooperate) as well as the single indicator of bounded authority onto age, gender, income, ethnicity, French vs. English language (in terms of filling in the survey) indicator, rural vs. urban indicator. But in addition, we also included victimization status (yes or no in the previous two years), perceived safety, and perceived disorder (we saved the scores from a 1-factor confirmatory factor analysis of the seven perceived disorder items to create a single index). ${ }^{3}$

Table 4 summarises the results. In terms of victimization, we find a consistent pattern: victims tend to be slightly more negative about the police than non-victims. Consistency is also there for perceived safety. People who are dissatisfied with safety in their neighbourhood tend to be more negative towards the police than people who are satisfied with safety. It is worth noting that the statistical effect of perceived safety is quite a bit stronger than victimisation status: victimization status is 0 or 1 and the coefficients are somewhere between -0.10 and -0.20 , while perceived safety ranges from 1 to 5 and the coefficients are somewhere between 0.25 and 0.50 . Perceived disorder is a relatively weak negative predictor - people who see disorder around them are more negative towards the police than people who do not (the index ranges from 0 to 4 and most of the coefficients are between -0.05 and -0.10 ). Finally, the statistical effects of income shrink towards zero when victimisation, perceived safety and perceived disorder are included in the various models. This suggests that lower-income individuals are more likely to be victims, feel unsafe, and perceive disorder around them, compared to higher-income individuals.

\section{Testing Procedural Justice Theory}

Figure 2 reports key findings from the fitted SEM that represents a test of PJT. Note that, because we are analysing cross-sectional survey data, we are not inferring causal pathways, and that adding in new variables could have an impact on parameter estimates.

Starting at the right-hand side of the model, we found that just over half $(57 \%)$ of the variation in cooperation can be explained by the various predictors. In particular, legitimacy is a strong predictor of cooperation $(B=.745, p<.001)$, as is engagement $(B=.353, p<.001)$ and distributive justice $(B=-.334, p<.001) .{ }^{4}$ These findings indicate that a good deal of variation in cooperation can be explained by legitimacy and engagement: people who view the police as legitimate and who believe that officers engage with the community are more likely to report willingness to cooperate with the police, compared to people who view the police as illegitimate and do not believe that officers engage with the community.

\footnotetext{
${ }^{3}$ A 1-factor CFA model fit the data well according to approximate fit statistics (RMSEA .046 [90\% CI .038, .056], CFI .995, TLI .993). Factor loadings and $\mathrm{R}^{2} \mathrm{~s}$ were all relatively high, indicating good scaling properties. The standardized factor loadings ranged from .69 to .86 and the $\mathrm{R}^{2} \mathrm{~s}$ ranged from .48 to .74 . The two indicators with the highest factor loadings were 'people hanging around on the streets' and 'people being drunk or rowdy in public places'.

${ }^{4}$ The negative partial association between distributive justice and cooperation requires comment. This can happen when explanatory variables are highly correlated with each other and the outcome variable. 'Collinearity' refers to the situation in which one explanatory variable is strongly correlated with another explanatory variable; 'multi-collinearity' refers to the situation in which one predictor variable can be linearly predicted by a combination of other predictor variables with a good deal of accuracy. To investigate, we ran the model again, but this time with just distributive justice predicting cooperation ( $B$ $=.49, p<.001)$. We then added procedural justice as a second predictor of cooperation $(B=.84, p<.001)$ alongside distributive justice $(B=-.25, p<.001)$. Note the sign-switch: positive without procedural justice in the regression model, negative with procedural justice in the regression model. This is because distributive justice is strongly correlated with procedural justice $(r=.88$ in this particular model). In such an instance, it can be a little artificial to think about the effect of a unit increase in one construct (here distributive justice) on the expected level of the outcome, while holding constant the other construct (here procedural justice). At any fixed value of procedural justice, there is not much variation in distributive justice, making it hard to tease out partial correlations with any accuracy. We therefore recommend caution when interpreting the estimated negative relationship between distributive justice and cooperation in Figure 2.
} 
Figure 2. Fitted SEM model testing procedural justice theory

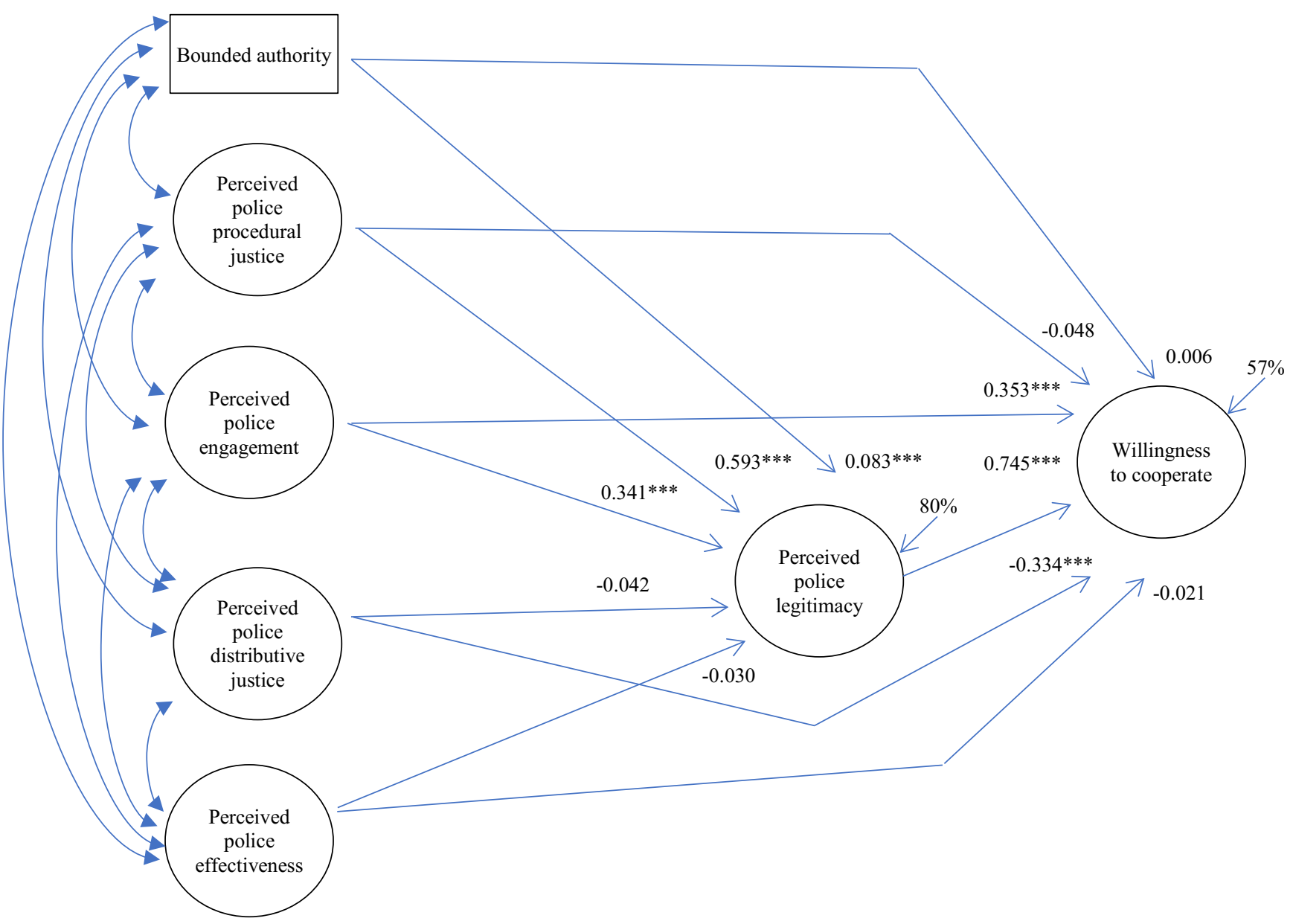

Turning to the predictors of legitimacy, we find that just over three-quarters $(80 \%)$ of the variation in legitimacy is explained by the various constructs in the model. Procedural justice and engagement again emerge as important. Procedural justice is a strong and positive predictor of legitimacy $(B=.59, p<.001)$ and engagement is a moderate and positive predictor of legitimacy $(B=$ $.34, p<.001)$. Of note is that bounded authority is a weak and positive predictor of legitimacy $(B=.08$, $p<.001)$. It is reasonable to conclude from this that procedural justice and engagement could be strong normative expectations about how police officers should behave among respondents; in other words, when officers violate these norms about how they are supposed to behave, they risk losing legitimacy in the eyes of those they serve and protect (although, of course, the data are observational so we can say little that is meaningful regarding cause and effect). Table 5 provides the bivariate correlations between the five constructs on the left-hand side of the model (Figure 2), which are consistent with the correlations presented in Table 2.

Table 5. Correlations between constructs from the fitted SEM

\begin{tabular}{|l|c|c|c|c|c|}
\hline Variables & $\begin{array}{c}\text { Bounded } \\
\text { authority }\end{array}$ & $\begin{array}{c}\text { Procedural } \\
\text { justice }\end{array}$ & $\begin{array}{c}\text { Community } \\
\text { engagement }\end{array}$ & $\begin{array}{c}\text { Distributive } \\
\text { justice }\end{array}$ & Effectiveness \\
\hline Bounded authority & ----- & & & & \\
\hline Procedural justice & $0.466^{* * *}$ & ------ & & & \\
\hline Community engagement & $0.395^{* * *}$ & $0.902^{* * *}$ & ------ & & \\
\hline Distributive justice & $0.406^{* * *}$ & $0.878^{* * *}$ & $0.837^{* * *}$ & ------ & \\
\hline Effectiveness & $0.318^{* * *}$ & $0.773^{* * *}$ & $0.835^{* * *}$ & $0.683^{* * *}$ & ----- \\
\hline
\end{tabular}

${ }^{*} p<0.05,{ }^{* *} p<0.01,{ }^{* * *} p<0.001$ 
What about police-citizen encounters? Figure 1 included two mediating layers (trust and legitimacy) between contact and cooperation. We re-estimated the SEM shown in Figure 2, this time including contact with the police as a predictor of trust. Three things are of note. First, there is asymmetry in the estimated statistical effects of contact, with negatively-received encounters being related to lower expected levels of cooperation, and positively-received encounters being related to higher expected levels of cooperation, but with the negative statistical effects being stronger than the positive statistical effects. Second, positive statistical effects are stronger for citizen-initiated contacts than police-initiated contacts. Third, the statistical pathways from contact to cooperation run largely via engagement, procedural justice and legitimacy. Negative contact is related to lower average levels of engagement, procedural justice and legitimacy, and lower average levels of engagement, procedural justice and legitimacy are related to lower levels of cooperation. Positive contact is related to higher average levels of engagement, procedural justice and legitimacy, and higher average levels of engagement, procedural justice and legitimacy are related to higher levels of cooperation.

Table 6. Indirect statistical effects of police-citizen contact on willingness to cooperate

\begin{tabular}{|l|l|l|}
\hline PATHWAY FROM & VIA ... TO COOPERATION & $B$ \\
\hline Police-initiated, negatively-received contact & Engagement to cooperation & $-.103^{* * *}$ \\
\hline Police-initiated, negatively-received contact & Procedural justice to legitimacy to cooperation & $-.097^{* * *}$ \\
\hline Police-initiated, negatively-received contact & Engagement to legitimacy to cooperation & $-.066^{* * *}$ \\
\hline Public-initiated, negatively-received contact & Engagement to cooperation & $-.065^{* * *}$ \\
\hline Public-initiated, negatively-received contact & Procedural justice to legitimacy to cooperation & $-.060^{* * *}$ \\
\hline Public-initiated, negatively-received contact & Engagement to legitimacy to cooperation & $-.041^{* * *}$ \\
\hline Police-initiated, positively-received contact & Engagement to cooperation & $.030^{* *}$ \\
\hline Police-initiated, positively-received contact & Procedural justice to legitimacy to cooperation & $.032^{* * *}$ \\
\hline Police-initiated, positively-received contact & Engagement to legitimacy to cooperation & $.019^{* *}$ \\
\hline Public-initiated, positively-received contact & Engagement to cooperation & $.051^{* * *}$ \\
\hline Public-initiated, positively-received contact & Procedural justice to legitimacy to cooperation & $.048^{* * *}$ \\
\hline Public-initiated, positively-received contact & Engagement to legitimacy to cooperation & $.032^{* * *}$ \\
\hline
\end{tabular}

${ }^{*} p<0.05,{ }^{* *} p<0.01, * * * p<0.001$

\section{Assessing Single Indicators}

The next stage of analysis shifts our attention towards identifying a sub-set of the 50 measures that can be used as a harmonised set of indicators across Canada (see Appendix A). Most of the constructs have been measured using multiple indicators. This is good practice. But it is important to be pragmatic. Can we use a smaller number of measures to adequately capture each of the various constructs? To inform our recommendations, we use four criteria:

1. Conceptual considerations (e.g., procedural justice is typically thought to have at least three aspects, namely fair treatment, fair decision-making, and voice provision);

2. Factor loadings in each of the CFAs reported in Tables 1 and 2;

3. Substitutability analysis in each of the CFAs (using a single indicator to predict a relevant latent construct); and,

4. Substitutability analysis in the predictors of each of the CFAs.

This subjective exercise involves balancing a number of different things in order to make concrete recommendations. A summary of our recommendations is provided in the next section.

\section{Procedural justice}

Starting with procedural justice, we recommend inclusion of three items, partly because procedural justice is itself multi-dimensional, and partly to reflect the central importance of PJT in explaining overall trust and legitimacy. In terms of decision-making, there were two measures in the original question-set. We recommend 'The police make decisions based on facts' because the other decision- 
making measure (i.e., 'About how often would you say that the police in your neighbourhood make fair, impartial decisions in the cases they deal with?') had the lowest factor loading in the CFA of procedural justice and the lowest regression coefficient when used as a single indicator of procedural justice predicting legitimacy (compared to the regression coefficient for procedural justice as a latent construct predicting legitimacy). The other decision-making measure performed the best in terms of demographic substitutability. Taken together, either of these indicators would be a good choice, however, we lean towards 'The police make decisions based on facts' because it performed better than the other decision-making measure on two of the three criteria.

The survey fielded a number of interpersonal treatment measures, as well as a few items that capture trustworthy motives (e.g., 'The [police service] is an organization with integrity', 'The police know how to carry out their official duties properly' and 'The [police service] is an open and transparent organization'). We recommend the measure 'The police treat people with respect' on the basis that it did the best across all three criteria. It had the second highest factor loading in the CFA of procedural justice and the second highest regression coefficient when used as a single indicator of procedural justice predicting legitimacy. It came 'mid-table' in terms of substitutability and it also has the advantage of being a little more specific compared, for instance, to 'The police treat people fairly.' Respondents may interpret 'fairly' in a broader range of ways compared to 'respect', not least because respect is often seen as part of fairness. An alternative measure that did reasonably well in the analysis is 'The police know how to carry out their official duties properly,' although its vagueness could be seen as both a strength and a weakness.

\section{Distributive justice}

In terms of distributive justice, we recommend 'The police provide the same quality of service to all citizens.' It had the highest factor loading in the CFA of distributive justice, the joint highest regression coefficient when used as a single indicator of distributive justice predicting legitimacy, and was joint first in terms of demographic substitutability. However, 'The police treat everyone fairly, regardless of who they are' did well too. This would be a good alternative, although its focus on equal fair treatment could be seen as a strength (it is arguably more specific than 'quality of service') and a weakness (it refers to fair interpersonal treatment and decision-making, albeit in terms of the equal allocation of procedural justice across groups in society).

\section{Community engagement}

Here, we recommend either 'The police are dealing with the things that matter to people in this community' or 'The police can be relied on to be there when you need them.' If forced to select a single item, we would select the former, since it more clearly relates to community preferences; however, both items perform well in terms of the factor loadings that emerged in the CFA of distributive justice, the regression coefficients that emerged when used as a single indicator of distributive justice predicting legitimacy, and substitutability.

\section{Effectiveness}

To measure effectiveness, we recommend the following two indicators: 'Responding quickly to calls for assistance?' and 'Resolving crimes where violence is involved?'. Both performed well in terms of the factor loadings that emerged in the CFA of effectiveness and the regression coefficients that emerged when each were used as a single indicator of effectiveness predicting legitimacy. In terms of substitutability, 'Responding quickly to calls for assistance?' performs less well; however, in this instance, we judge the performance on the other two criteria to be most diagnostic. It is worth noting that these two items relate to distinct aspects of the police 'mission' - dealing with crime and assisting people in need.

\section{Legitimacy}

As mentioned earlier, scholars typically differentiate between the normative appropriateness of an institution and the extent to which people feel a moral duty to obey the orders of actors that embody an institution. There was only one measure of the second dimension, so we recommend 'I feel a moral duty to follow police orders.' There were two measures of the first dimension, and we recommend ' $I$ 
generally support how the police usually act' because it performed better than the other measure on the three criteria.

\section{Cooperation}

Turning to cooperation with police, we recommend the following two measures: 'I would call the police for assistance' and 'I would help the police if asked'. As with effectiveness, both perform similarly well in terms of the factor loadings that emerged in the CFA of cooperation and the regression coefficients that emerged when used as a single indicator of legitimacy predicting cooperation. In terms of substitutability, 'I would call the police for assistance' performs less well, but we judge the performance on the other two criteria to be most diagnostic. Again, it is worth noting that even though both load on the same latent construct, which we label cooperation, these two items refer to somewhat different things - the first refers to assistance for the self, while the second refers to a police-initiated call for assistance. On balance, we recommend 'I would help the police if asked' .

\section{Validating the Single Item Measures}

By way of illustration, Figure 3 provides the findings from a path analysis model that uses single indicators rather than latent constructs. ${ }^{5}$ The findings are generally consistent with the structural equation modelling (Figure 2), which we find reassuring.

Figure 3. Fitted path analysis model testing PJT

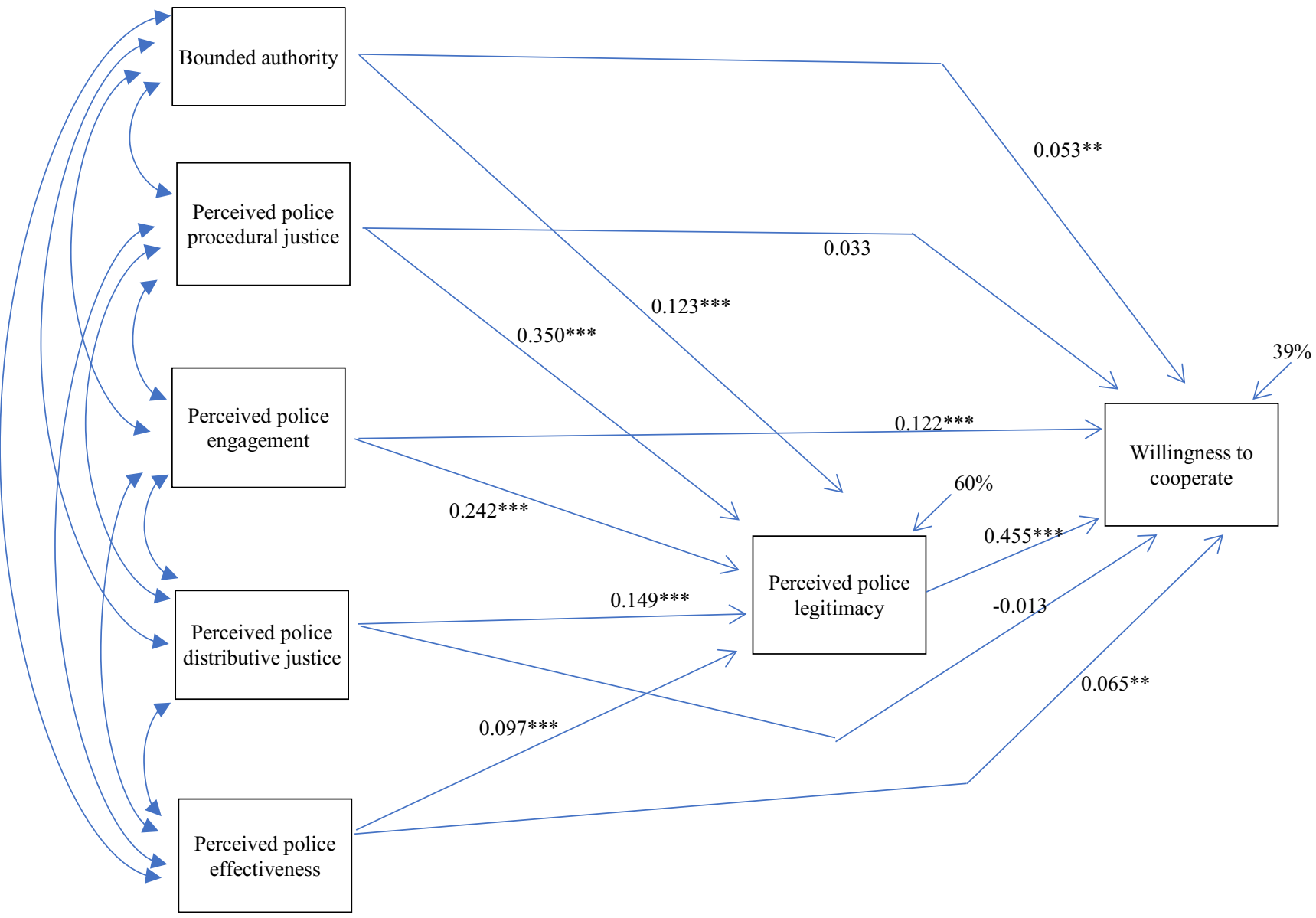

\footnotetext{
${ }^{5}$ The measures used were: 'about how often would you say that the police in your neighbourhood exceed their authority' (bounded authority), 'the police treat people with respect' (procedural justice), 'the police are dealing with the things that matter to people in this community' (engagement), 'the police provide the same quality of service to all citizens', 'how effective are the police at resolving crimes where violence is involved?' (effectiveness), 'I generally support how the police usually act' (legitimacy), and 'I would help the police if asked' (cooperation).
} 


\section{Recommendations for 10-15 Survey Items}

The goal of this study was to identify the 10-15 key survey items to harmonise future research into public opinions of the police. The survey of 2,527 Canadians fielded 50 survey items measuring 9 constructs relevant to public attitudes towards the police:

- Police contact and satisfaction with contact

- Overall 'trust and confidence'

- Procedural justice

- Distributive justice

- Community engagement

- Bounded authority (respecting the limits of one's rightful authority)

- Effectiveness

- Legitimacy

- Willingness to cooperate

\section{Police Contact and Satisfaction with Contact Indicators}

The first construct (whether an individual has had recent contact with the police and satisfaction with how the police officer treated him/her) involves two indicators for police-initiated contact and two indicators for citizen-initiated contact. These should be included in surveys wherever possible, and could be considered as supplements to the final 10-15 item index. Police-initiated contact was measured as follows:

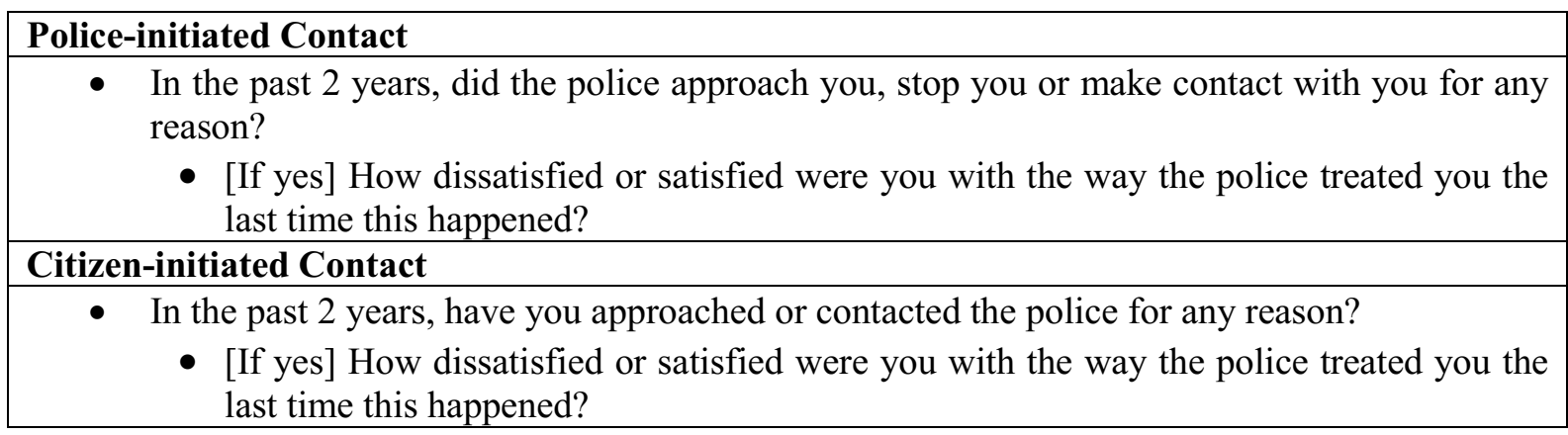

It is important to ask about both types of contact, in part because research suggests that negativelyexperienced police-initiated contact may have a stronger negative effect on trust and legitimacy compared to negatively-experienced citizen-initiated contact.

\section{Overall Trust and Confidence Indicators}

We also recommend the following two confidence indicators. While these have not been discussed in any detail above, we are broadly convinced by the argument that easy to understand 'headline' measures are useful for policy-makers and others - our decision here is therefore practical as much as conceptual. These items could be validated by further work which, for example, explores the extent the specific components of trust predict responses to overall 'trust and confidence' items (see Jackson \& Bradford 2010, who found, using a London-based sample, that trust in fairness and engagement was very strongly correlated with overall trust and confidence):

\section{Overall Trust and Confidence}

- Taking everything into account, how good a job do you think the police in this area are doing? 
- Taking everything into account, how good a job do you think the police in this country are doing?

These two items have the additional benefit of allowing a clear and easy distinction between local and national police; prior research suggests that people do tend to differentiate at this level to at least some degree.

The above makes up either 4 indicators or 6 indicators, depending on whether one includes both types of police-citizen contact. However, it might be worth thinking about having 10-15 measures of public attitudes in addition to the contact/satisfaction indicators, which are arguably explanatory variables (e.g., akin to age, ethnicity and other explanatory items). This would leave us with 2 indicators (the two overall trust/confidence measures).

\section{Public Attitude Indicators}

In addition to the above, we recommend the following ten indicators ${ }^{6}$ :

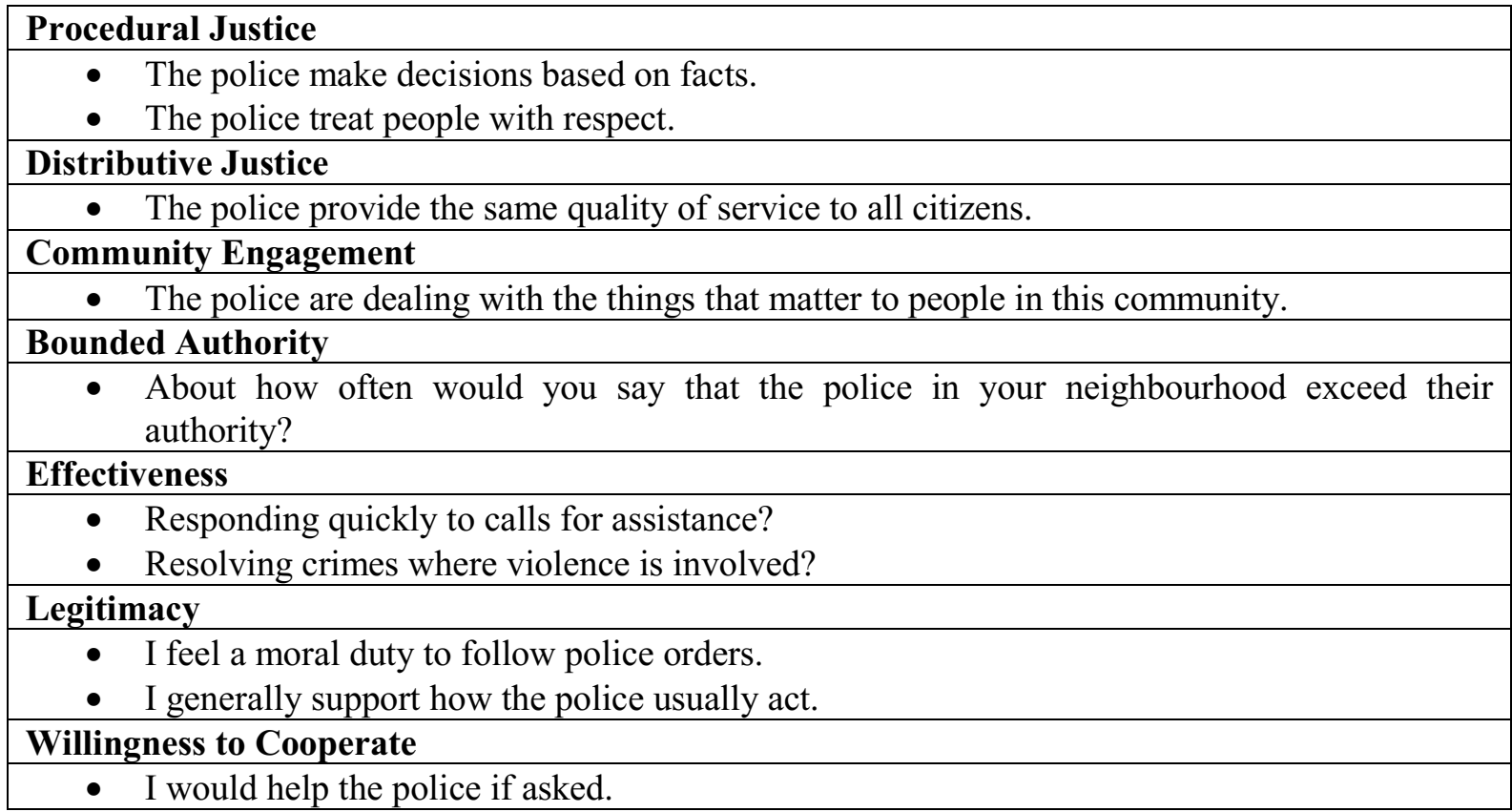

This would take us to 12 indicators, assuming the contact/satisfaction measures are not included in the 'core indicator' count, with the order of questions following the above (with the one exception being to have the overall summary trust/confidence measures at the end). We would suggest keeping the wording, given the importance of piloting. We also recommend including measures of gender, age, income, ethnicity, urban/rural and recent victimization, alongside a measure of perceived safety ('In general, how satisfied are you with your personal safety from crime?') and some indicators of perceived disorder (in the current study the two best performing measures, at least according to factor analysis, were 'In your neighbourhood, how much of a problem are people hanging around on the streets?' and 'In your neighbourhood, how much of a problem are people being drunk or rowdy in public places?').

\footnotetext{
${ }^{6}$ See Appendix A for details and alternative recommended items.
} 


\section{References}

Baier, A. (1986). Trust and antitrust. Ethics, 96, 231-260.

Barber, B. (1983). The logic and limits of trust. New Brunswick, NJ: Rutgers University Press.

Bauer, P. C. (2014). Conceptualizing and measuring trust and trustworthiness. Political Concepts: Committee on Concepts and Methods Working Paper Series, 61, 1-27.

Bottoms, A., \& Tankebe, J. (2012). Beyond procedural justice: A dialogic approach to legitimacy in criminal justice. Journal of Criminal Law and Criminology, 102(1) 101-150.

Bradford, B. (2010). Convergence, not divergence? Trends and trajectories in public contact and confidence in the police. British Journal of Criminology, 51(1), 179-200.

Bradford, B., Hohl, K., Jackson, J., \& MacQueen, S. (2015). Obeying the rules of the road: Procedural justice, social identity and normative compliance, Journal of Contemporary Criminal Justice, $31,151-170$.

Bradford, B., \& Jackson, J. (2016). Cooperating with the police as informal social control: Trust and neighbourhood concerns as predictors of public assistance. Nordisk politiforskning (Nordic Journal of Policing Studies), 3(2), 109-129.

Bradford, B., Huq A., Jackson, J., \& Roberts, B. (2014). What price fairness when security is at stake? Police legitimacy in South Africa. Regulation and Governance, 8(2), 246-268.

Brandl, S. G., Frank, J., Worden, R. E., \& Bynum, T. S. (1994). Global and specific attitudes toward the police: disentangling the relationship. Justice Quarterly, 11(1), 119-134.

Cao, L., Frank, J., \& Cullen, F. T. (1996). Race, community context and confidence in the police. American Journal of Police, 15, 3-22.

Coicaud, J. M. (2002). Legitimacy and politics: a contribution to the study of political right and political responsibility. Cambridge, United Kingdom: Cambridge University Press.

Colquitt, J. A., Scott, B. A., \& LePine, J. A. (2007). Trust, trustworthiness, and trust propensity: A meta-analytic test of their unique relationships with risk taking and job performance. Journal of Applied Psychology, 92, 909-927.

Flexon, J. L., Lurigio, A. J., \& Greenleaf, R. G. (2009). Exploring the dimensions of trust in the police among Chicago juveniles. Journal of Criminal Justice, 37, 180-189.

Gambetta, D. (1988). Trust: Making and breaking cooperative relations. Cambridge, MA: Basil Blackwell.

Hamm, J. A., Trinkner, R., \& Carr, J. D. (2017). Fair process, trust, and cooperation: moving toward an integrated framework of police legitimacy. Criminal Justice and Behavior, 44, 1183-1212.

Hardin, R. (2006). Trust and trustworthiness. New York, NY: Russel Sage Foundation.

Hawdon, J. (2008). Legitimacy, trust, social capital, and policing styles: A theoretical statement. Police Quarterly, 11, 182-201. 
Hough, M., Jackson, J., \& Bradford, B. (2013). The drivers of police legitimacy: Some European research. Journal of Policing, Intelligence and Counter Terrorism 8(2): 144-165.

Hu, L. T., \& Bentler, P. M. (1999). Cutoff criteria for fit indexes in covariance structure analysis: Conventional criteria versus new alternatives. Structural equation modeling: a multidisciplinary journal, 6(1), 1-55.

Huq, A., Jackson, J., \& Trinkner, R. (2017). Legitimating practices: Revisiting the predicates of police legitimacy. British Journal of Criminology, 57(5), 1101-1122.

Jackson, J. (2018). Norms, normativity and the legitimacy of justice institutions: International perspectives. Annual Review of Law and Social Science, 14, 145-165.

Jackson, J., \& Bradford, B. (2009). Crime, policing and social order: On the expressive nature of public confidence in policing. British Journal of Sociology, 60(3): 493-521.

Jackson, J., Bradford, B., Hough, M., Myhill, A., Quinton, P., \& Tyler, T.R. (2012). Why do people comply with the law? Legitimacy and the influence of legal institutions. British Journal of Criminology, 52(6), 1051-1071.

Jackson J., Bradford, B., Stanko, B., \& Hohl, K. (2013). Just authority? Trust in the police in England and Wales. London, United Kingdom: Routledge.

Jackson, J., \& Gau, J. (2015). Carving up concepts? Differentiating between trust and legitimacy in public attitudes towards legal authority.. In E. Shockley, T. M. S. Neal, L. PytlikZillig, \& B. and Bornstein (Eds.), Interdisciplinary perspectives on trust: Towards theoretical and methodological integration (pp. 49-69). New York, NY: Springer.

Jackson, J., Huq, A., Bradford, B., \& Tyler, T. R. (2013). Monopolizing force? Police legitimacy and public attitudes towards the acceptability of violence. Psychology, Public Policy and Law, 19(4), 479-497.

Jackson, J., \& Kuha, J. (2016). How theory guides measurement: Public attitudes toward crime and policing. In T. S. Bynum \& B. M. Huebner (Eds.), Handbook on measurement issues in criminology and criminal justice (pp. 377-415). Chichester, West Sussex: John Wiley \& Sons, Inc..

Johnson, D., Maguire, E.R., \& Kuhns, J.B. (2014). Public perceptions of the legitimacy of the law and legal authorities: Evidence from the Caribbean. Law and Society Review, 48, 947-978.

Lind, E., \& Tyler, T. (1988). The social psychology of procedural justice. New York, NY: Plenum Press.

Mayer, R. C., Davis, J. H., \& Schoorman, F. D. (1995). An integrative model of organizational trust. Academy of Management Review, 20, 709-734.

McEvily, B. (2011). Reorganizing the boundaries of trust: From discrete alternatives to hybrid forms. Organization Science, 22, 1266-1276.

Möllering, G. (2001). The nature of trust: From Georg Simmel to a theory of expectation, interpretation and suspension. Sociology, 35, 403-420.

President's Task Force on 21st Century Policing (2015). President's task force on 21st century policing implementation guide: Moving from recommendations to action. Washington, DC: 
Office of Community Oriented Policing Services. Retrieved from http://www.cops.usdoj. gov/pdf/taskforce/Implementation_Guide.pdf

Public Safety Canada (2004). Public confidence in the criminal justice system Research summary of the following report: J. V. Roberts (2004). Public confidence in criminal justice: A review of recent trends (User Report 2004-05). Ottawa, Canada: Public Safety Canada. Retrieved from https://www.publicsafety.gc.ca/cnt/rsrcs/pblctns/pblc-cnfdnc/index-en.aspx

PytlikZillig, L. M., \& Kimbrough, C. D. (2016). Consensus on conceptualizations and definitions of trust: Are we there yet? In E. Shockley, T. M. S. Neal, L. M. PytlikZillig, \& B H. Bornstein (Eds.), Interdisciplinary perspectives on trust: Towards theoretical and methodological integration (pp. 17-47). New York, NY: Springer.

Reisig, M. D., \& Parks, R. B. (2000). Experience, quality of life, and neighborhood context: A hierarchical analysis of satisfaction with police. Justice Quarterly, 17, 607-630.

Reisig, M. D., Bratton, J. \& Gertz, M. G. (2007). The construct validity and refinement of processbased policing measures. Criminal Justice and Behavior, 34, 1005-1027.

Schilke, O., \& Cook, K. S. (2013). A cross-level process theory of trust development in interorganizational relationships. Strategic Organization, 11, 281-303.

Sunshine, J., \& Tyler, T. R. (2003). The role of procedural justice and legitimacy in public support for policing. Law and Society Review, 37, 513-548.

Thibaut, J. \& Walker, L. (1975). Procedural justice: A psychological analysis. Hillsdale, NJ: Erlbaum.

Trinkner, R., Jackson, J., \& Tyler, T. R. (2018). Bounded authority: Expanding “appropriate” police behavior beyond procedural justice. Law and Human Behavior, 42(3), 280-293.

Tuch, S. A., \& Weitzer, R. (1997). Trends: Racial differences in attitudes toward the police. Public Opinion Quarterly, 61(4), 642-663.

Tyler, T. R., \& Jackson, J. (2013). Future challenges in the study of legitimacy and criminal justice. In J. Tankebe \& A. Liebling (Eds.), Legitimacy and criminal justice: An international exploration (pp. 83-104). Oxford, United Kingdom: Oxford University Press.

Tyler, T. R. (1989). The psychology of procedural justice: A test of the group-value model. Journal of Personality and Social Psychology, 57, 830-838.

Tyler, T. R. (1990). Why People Obey the Law. New Haven, CT: Yale University Press.

Tyler, T. R. (1994). Psychological models of the justice motive. Journal of Personality and Social Psychology, 67, 850-863.

Tyler, T. R. (2003). Procedural justice, legitimacy, and the effective rule of law. In M. Tonry (Ed.), Crime and justice: A review of research (vol. 30, pp. 431-505). Chicago, IL: University of Chicago Press.

Tyler, T. R. (2004). Enhancing police legitimacy. The Annals of the American Academy, 593, 84-99.

Tyler, T. R. (2006). Psychological perspectives on legitimacy and legitimation. Annual Review of Psychology, 57, 375-400. 
Tyler, T. R. (2009). Legitimacy and criminal justice: The benefits of self-regulation. Ohio State Journal of Criminal Law, 7, 307-359.

Tyler, T. R., \& Jackson, J. (2014). Popular legitimacy and the exercise of legal authority: Motivating compliance, cooperation and engagement. Psychology, Public Policy and Law, 20, 1, 78-95.

Tyler, T. R., Jackson, J., \& Mentovich, A. (2015). On the consequences of being a target of suspicion: Potential pitfalls of proactive police contact. Journal of Empirical Legal Studies, 12(4), 602636.

Tyler, T.R. (1988). What is procedural justice? Criteria used by citizens to assess the fairness of legal procedures. Law and Society Review, 22, 103-135.

Tyler, T.R., \& Huo, Y.J. (2002). Trust in the law. New York, NY: Russell Sage Foundation.

Van Damme, A., Pauwels, L., \& Svensson, R. (2015). Why do Swedes cooperate with the police? A SEM analysis of Tyler's procedural justice model. European Journal of Criminal Policy Research, 21(1), 15-33.

Van den Bos, K., Lind, E. A., Vermunt, R., \& Wilke, H. A. (1997). How do I judge my outcome when I do not know the outcome of others? The psychology of the fair process effect. Journal of Personality and Social Psychology, 72(5), 1034-1046. 


\section{Appendix A: Detailed Results of Data Analyses}

\section{CFA for English-language questionnaire and French-language questionnaire}

\section{CFA from 6 factor solution [STDYX]}

\section{Procedural justice}

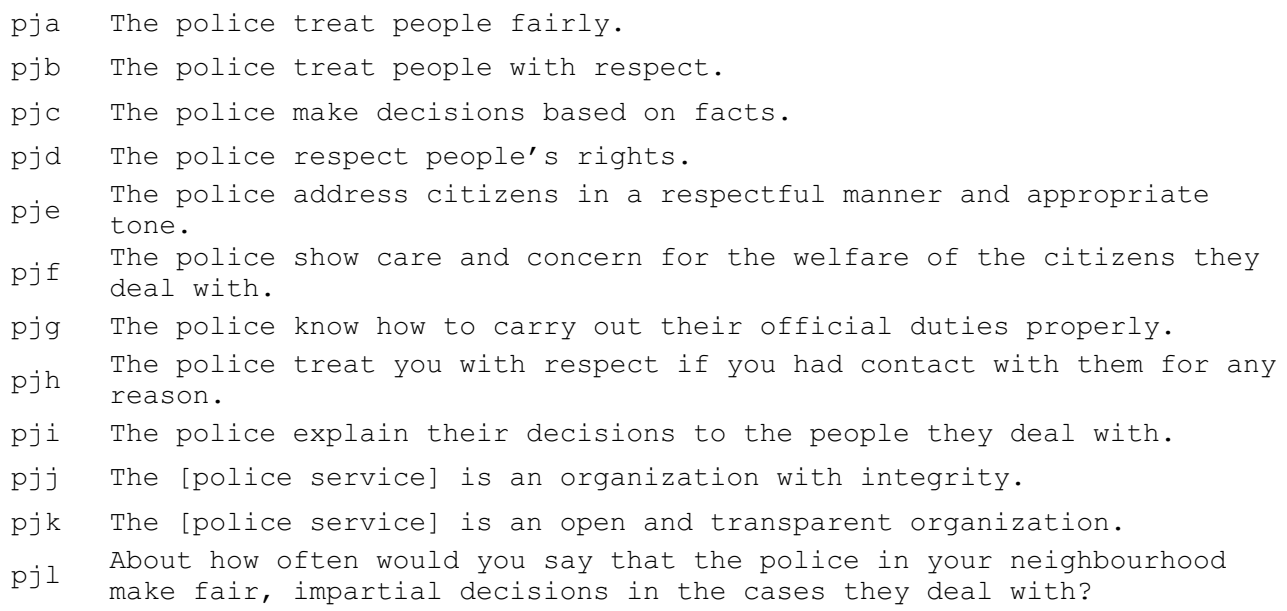

\section{Distributive justice}

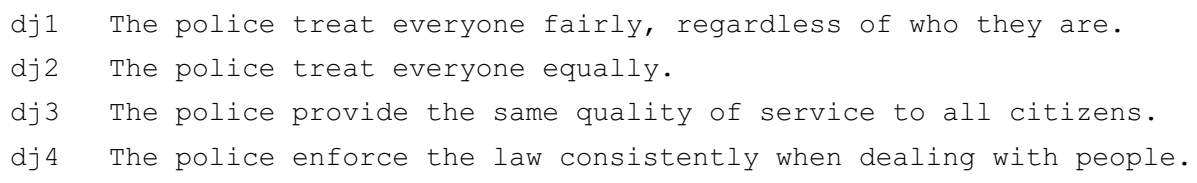

\section{Engagement}

eng

1 The police understand the issues that affect this community.

eng The police are dealing with the things that matter to people in this 2 community.

eng

eng
The police can be relied on to be there when you need them.

The police are sensitive to the needs of different cultures.
Englis Frenc

$\begin{array}{cc}h & h \\ 0.855 & 0.887 \\ 0.864 & 0.901 \\ 0.863 & 0.861 \\ 0.847 & 0.852\end{array}$

effl Resolving crimes where violence is involved?

\section{Legitimacy}

nal The police generally have the same sense of right and wrong as I do.

\section{Cooperation}

coopl I would help the police if asked. 
coop3 I would call the police to report a crime.

coop4 I would report suspicious activities to police.

coop5 I would help the police by giving evidence in court.

English-language questionnaire: Correlations between latent constructs from the six factor CFA model (plus the single indicator of bounded authority)

\begin{tabular}{|l|c|c|c|c|c|c|c|}
\hline & 1 & 2 & 3 & 4 & 5 & 6 & 7 \\
\hline 1 Bounded authority & - & & & & & & \\
\hline 2 Procedural justice & $.50^{* * *}$ & - & & & & & \\
\hline 3 Engagement & $.43^{* * *}$ & $.91^{* * *}$ & - & & & & \\
\hline 4 Distributive justice & $.42^{* * *}$ & $.88^{* * *}$ & $.85^{* * *}$ & - & & & \\
\hline 5 Effectiveness & $.35^{* * *}$ & $.80^{* * *}$ & $.86^{* * *}$ & $.71^{* * *}$ & - & & \\
\hline 6 Legitimacy & $.49^{* * *}$ & $.88^{* * *}$ & $.86^{* * *}$ & $.77^{* * *}$ & $.74^{* * *}$ & - & \\
\hline 7 Willingness to cooperate & $.37^{* * *}$ & $.63^{* * *}$ & $.66^{* * *}$ & $.47^{* * *}$ & $.56^{* * *}$ & $.73^{* * *}$ & - \\
\hline
\end{tabular}

${ }^{*} p<0.05,{ }^{* *} p<0.01,{ }^{* * *} p<0.001$

French-language questionnaire: Correlations between latent constructs from the six factor CFA model (plus the single indicator of bounded authority)

\begin{tabular}{|c|c|c|c|c|c|c|c|}
\hline & 1 & 2 & 3 & 4 & 5 & 6 & 7 \\
\hline 1 Bounded authority & - & & & & & & \\
\hline 2 Procedural justice & $.54 * * *$ & - & & & & & \\
\hline 3 Engagement & $.44 * * *$ & $.87 * * *$ & - & & & & \\
\hline 4 Distributive justice & $.50 * * *$ & $.86^{* * *}$ & $.80 * * *$ & - & & & \\
\hline 5 Effectiveness & $.34 * * *$ & $.70 * * *$ & $.77 * * *$ & $.61 * * *$ & - & & \\
\hline 6 Legitimacy & $.55 * * *$ & $.87 * * *$ & $.82 * * *$ & $.80 * * *$ & $.63 * * *$ & - & \\
\hline 7 Willingness to cooperate & $.35 * * *$ & $.61 * * *$ & $.62 * * *$ & $.52 * * *$ & $.49 * * *$ & $.74 * * *$ & - \\
\hline
\end{tabular}

${ }^{*} p<0.05,{ }^{* *} p<0.01,{ }^{* * *} p<0.001$ 


\section{CFA for rural and urban respondents}

\section{CFA from 6 factor solution [STDYX]}

\section{Procedural justice}

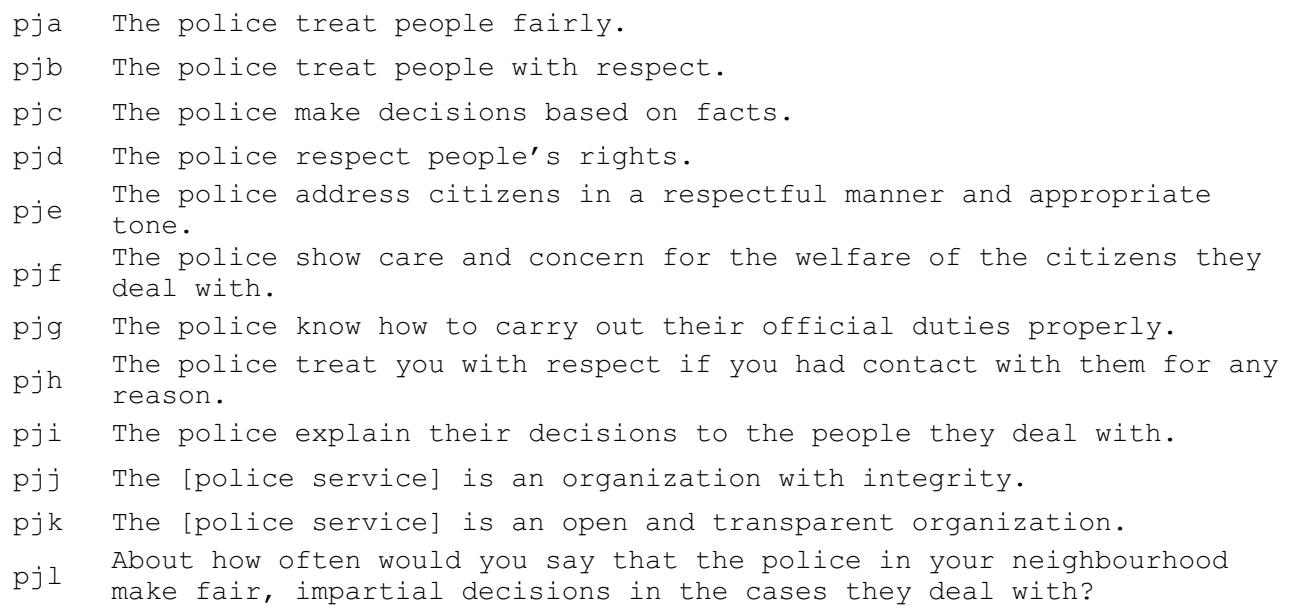

Rural

\section{Distributive justice}

dj1 The police treat everyone fairly, regardless of who they are.

dj2 The police treat everyone equally.

dj3 The police provide the same quality of service to all citizens.

dj4 The police enforce the law consistently when dealing with people.

$\begin{array}{ll}\text { Rural } & \text { Urban } \\ 0.990 & 0.954 \\ 0.944 & 0.946 \\ 0.959 & 0.958 \\ 0.915 & 0.926\end{array}$

\section{Engagement}

eng1 The police understand the issues that affect this community. The police are dealing with the things that matter to people in this eng2 community.

eng3 The police can be relied on to be there when you need them.

eng4 The police are sensitive to the needs of different cultures.

Rural Urban

$0.870 \quad 0.862$

$0.892 \quad 0.865$

$0.878 \quad 0.862$

0.8520 .848

\section{Effectiveness}

effl Resolving crimes where violence is involved?

\section{Legitimacy}

\section{Cooperation}

coopl I would help the police if asked.

coop2 I would call the police for assistance.

coop3 I would call the police to report a crime. 
Rural: Correlations between latent constructs from the six factor CFA model (plus the single indicator of bounded authority)

\begin{tabular}{|l|c|c|c|c|c|c|c|}
\hline & 1 & 2 & 3 & 4 & 5 & 6 & 7 \\
\hline 1 Bounded authority & - & & & & & & \\
\hline 2 Procedural justice & $.55^{* * *}$ & - & & & & & \\
\hline 3 Engagement & $.47^{* * *}$ & $.88^{* * *}$ & - & & & & \\
\hline 4 Distributive justice & $.51^{* * *}$ & $.88^{* * *}$ & $.83^{* * *}$ & - & & & \\
\hline 5 Effectiveness & $.38^{* * *}$ & $.70^{* * *}$ & $.81^{* * *}$ & $.61^{* * *}$ & - & & \\
\hline 6 Legitimacy & $.55^{* * *}$ & $.89^{* * *}$ & $.85^{* * *}$ & $.81^{* * *}$ & $.66^{* * *}$ & - & \\
\hline 7 Willingness to cooperate & $.40^{* * *}$ & $.61^{* * *}$ & $.65^{* * *}$ & $.49^{* * *}$ & $.52^{* * *}$ & $.70^{* * *}$ & - \\
\hline
\end{tabular}

${ }^{*} p<0.05,{ }^{* *} p<0.01,{ }^{* * *} p<0.001$

Urban: Correlations between latent constructs from the six factor CFA model (plus the single indicator of bounded authority)

\begin{tabular}{|l|c|c|c|c|c|c|c|}
\hline & 1 & 2 & 3 & 4 & 5 & 6 & 7 \\
\hline 1 Bounded authority & - & & & & & & \\
\hline 2 Procedural justice & $.50 * * *$ & - & & & & & \\
\hline 3 Engagement & $.42 * * *$ & $.91 * * *$ & - & & & & \\
\hline 4 Distributive justice & $.42 * * *$ & $.88^{* * *}$ & $.84 * * *$ & - & & & \\
\hline 5 Effectiveness & $.34 * * *$ & $.80 * * *$ & $.84 * * *$ & $.70 * * *$ & - & & \\
\hline 6 Legitimacy & $.50 * * *$ & $.88^{* * *}$ & $.85 * * *$ & $.77 * * *$ & $.73 * * *$ & - & \\
\hline 7 Willingness to cooperate & $.35 * * *$ & $.62 * * *$ & $.65 * * *$ & $.49 * * *$ & $.55^{* * *}$ & $.74 * * *$ & - \\
\hline
\end{tabular}

${ }^{*} p<0.05,{ }^{* *} p<0.01,{ }^{* * *} p<0.001$ 


\section{Substitutability analysis}

\section{Procedural justice}

Conceptual priority: procedural justice is generally seen to include (a) interpersonal treatment, (b) decision-making, and (c) voice. Trustworthy motives is also sometimes included in the concept.

One of the following two decision-making indicators:

- $\quad$ pjc The police make decisions based on facts. [best overall in terms of the analysis]

- pjl About how often would you say that the police in your neighbourhood make fair, impartial decisions in the cases they deal with?

One of the following interpersonal treatment indicators:

- pjb The police treat people with respect. [best overall in terms of the analysis]

- $\quad$ jjd The police respect people's rights.

- pja The police treat people fairly

CFA from 6 factor solution [STDYX]

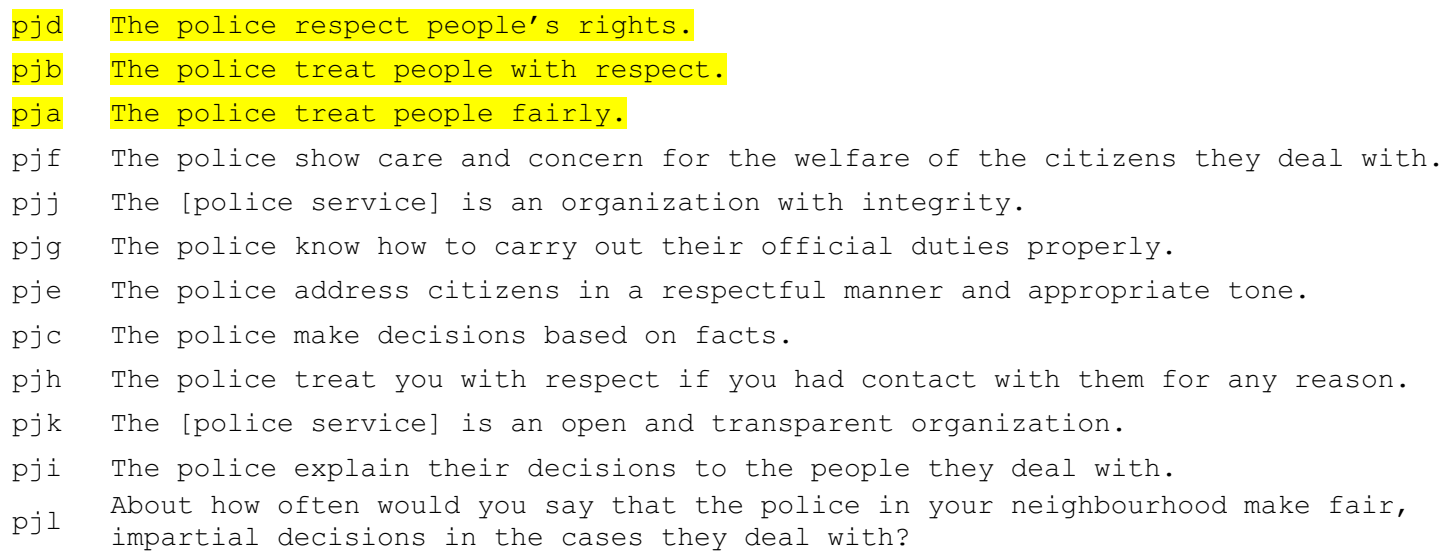

CFA substitutability analysis [STDYX]

$\begin{array}{llr}\text { Base- } & \text { Procedural justice predicting legitimacy (no other predictors) } & 0.879 \\ & & \\ \text { pjg } & \text { The police know how to carry out their official duties properly. } & 0.755 \\ \text { pjb } & \text { The police treat people with respect. } & 0.751 \\ \text { pjf } & \text { The police show care and concern for the welfare of the citizens they deal with. } & 0.738 \\ \text { pjj } & \text { The [police service] is an organization with integrity. } & 0.738 \\ \text { pjd } & \text { The police respect people's rights. } & 0.737 \\ \text { pja } & \text { The police treat people fairly. } & 0.731 \\ \text { pjc } & \text { The police make decisions based on facts. } & 0.715 \\ \text { pje } & \text { The police address citizens in a respectful manner and appropriate tone. } & 0.709 \\ \text { pjh } & \text { The police treat you with respect if you had contact with them for any reason. } & 0.688 \\ \text { pjk } & \text { The [police service] is an open and transparent organization. } & 0.664 \\ \text { pji } & \text { The police explain their decisions to the people they deal with. } & 0.607 \\ \text { pjl } \text { About how often would you say that the police in your neighbourhood make fair, } & 0.556\end{array}$


$\begin{array}{ll}\text { Public Safety } & \text { Sécurité publique } \\ \text { Canada } & \text { Canada }\end{array}$

Demographic substitutability analysis

Base-

Demographics predicting procedural justice

Female

Inco

0.006

0.044

0.045

White

South
Asian

Chinese

Black

About how often would you say that the police in your neighbourhood make fair, impartial decisions in the cases they deal with?

The police explain their decisions to the people they deal with.

0.003

0.055

0.093

0.079

0.531

$-0.008$

$-0.391$

The [police service] is an open and transparent organization.

The police address citizens in a respectful manner and appropriate tone.

The police treat people with respect.

The police respect people's rights.

The police show care and concern for the welfare of the citizens they deal with.

The [police service] is an organization with integrity.

0.030

0.006

0.141

0.226

$-0.102$

$-0.067$

$-0.003$

0.415

0.157

$-0.147$

$-0.372$

$0.006 \quad 0.005$

0.038

0.051

0.486

$-0.073$

$-0.385$

0.030

0.491

$-0.031$

$-0.392$

$0.005 \quad 0.051$

0.051

0.055

0.507

0.008

$-0.407$

$\begin{array}{llll}0.154 & 0.515 & -0.045 & -0.315\end{array}$

$-0.480$

$0.007 \quad 0.046$

0.048

0.081

0.542

0.007

0.076

0.615

0.022

$-0.466$

The police make decisions based on facts.

The police treat you with respect if you had contact with them for any reason.

pjg The police know how to carry out their official duties properly.

0.017

0.023

0.129

0.574

0.059

$-0.462$

$-0.502$

0.046

0.160

.470

$-0.353$ 
Cablic Safety Sécurité publique

$-0.091$

$-0.090$

0.490

$-0.059$

$-0.093$ 
Conceptual priority:

The best in terms of analysis are:

- $\quad$ dj3 The police provide the same quality of service to all citizens.

- $\quad$ dj1 The police treat everyone fairly, regardless of who they are.

CFA from 6 factor solution [STDYX]

dj3 The police provide the same quality of service to all citizens. 0.962

dj1 The police treat everyone fairly, regardless of who they are. 0.955

$\begin{array}{ll}\text { dj2 The police treat everyone equally. } & 0.947\end{array}$

dj4 The police enforce the law consistently when dealing with people. 0.923

CFA substitutability analysis [STDYX]

Base-

Distributive justice predicting legitimacy (no other predictors)

0.780

dj3 The police provide the same quality of service to all citizens. 
$\begin{array}{ll}\text { Public Safety } & \text { Sécurité publique } \\ \text { Canada } & \text { Canada }\end{array}$

Demographic substitutability analysis

Base-

Demographics predicting distributive justice

The police enforce the law consistently when dealing with people.

The police treat everyone fairly, regardless of who they are.

The police provide the same quality of service to all citizens.

The police treat everyone equally.

Base-

line

$\operatorname{dj} 1$

dj 4

dj 3

dj 2

Demographics predicting distributive justice

The police treat everyone fairly, regardless of who they are. The police enforce the law consistently when dealing with people. The police provide the same quality of service to all citizens.

The police treat everyone equally.

\begin{tabular}{|c|c|c|c|c|c|c|c|}
\hline Age & Female & Income & White & $\begin{array}{l}\text { South } \\
\text { Asian }\end{array}$ & Chinese & Black & $\begin{array}{c}\text { Sum of } \\
\text { diffs } \\
\text { (abs } \\
\text { values) }\end{array}$ \\
\hline 0.004 & -0.007 & 0.031 & 0.047 & 0.646 & 0.158 & -0.317 & \\
\hline 0.003 & 0.029 & 0.024 & -0.02 & 0.514 & 0.038 & -0.395 & 1.02 \\
\hline 0.005 & -0.041 & 0.029 & 0.041 & 0.539 & 0.136 & -0.389 & 1.18 \\
\hline 0.004 & 0.002 & 0.034 & 0.089 & 0.791 & 0.18 & -0.206 & 1.31 \\
\hline 0.004 & -0.017 & 0.032 & 0.069 & 0.693 & 0.247 & -0.268 & 1.33 \\
\hline Victim & $\begin{array}{c}\text { Perceived } \\
\text { safety }\end{array}$ & $\begin{array}{l}\text { Perceived } \\
\text { disorder }\end{array}$ & & $\begin{array}{l}\text { of dif } \\
s \text { values }\end{array}$ & & & \\
\hline-0.167 & 0.360 & -0.077 & & & & & \\
\hline-0.179 & 0.361 & -0.079 & & 0.02 & & & \\
\hline-0.140 & 0.353 & -0.077 & & 0.03 & & & \\
\hline-0.206 & 0.366 & -0.077 & & 0.05 & & & \\
\hline-0.199 & 0.328 & -0.086 & & 0.07 & & & \\
\hline
\end{tabular}




\section{Engagement}

The best in terms of analysis are:

- eng2 The police are dealing with the things that matter to people in this community.

- $\quad$ eng3 The police can be relied on to be there when you need them.

CFA from 6 factor solution [STDYX]

eng2 The police are dealing with the things that matter to people in this community.

eng1 The police understand the issues that affect this community.

eng3 The police can be relied on to be there when you need them.

CFA substitutability analysis [STDYX]

Base- 
Public Safety Sécurité publique
Canada

Demographic substitutability analysis

Base-

Demographics predicting engagement

The police are dealing with the things that matter to people in this community.

The police can be relied on to be there when you need them.

The police understand the issues that affect this community.

The police are sensitive to the needs of different cultures.

Base-

line

eng1

eng3

eng2

eng 4

Demographics predicting engagement

The police understand the issues that affect this community.

The police can be relied on to be there when you need them.

The police are dealing with the things that matter to people in this community.

The police are sensitive to the needs of different cultures.

$\begin{array}{cccccccc}\text { Age } & \text { Female } & \text { Income } & \text { White } & \begin{array}{c}\text { South } \\ \text { Asian }\end{array} & \text { Chinese } & \text { Black } & \begin{array}{c}\text { Sum of } \\ \text { diffs } \\ \text { (abs } \\ \text { values) }\end{array} \\ 0.007 & 0.07 & 0.054 & 0.083 & 0.656 & 0.035 & -0.409 & \\ 0.008 & 0.09 & 0.057 & 0.046 & 0.593 & 0.012 & -0.166 & 0.97 \\ 0.006 & 0.074 & 0.055 & 0.092 & 0.685 & -0.045 & -0.239 & 1.20 \\ 0.007 & 0.114 & 0.063 & 0.109 & 0.568 & 0.067 & -0.397 & 1.33 \\ 0.004 & -0.021 & 0.028 & 0.069 & 0.684 & 0.097 & -0.707 & 1.61\end{array}$

Victim

Perceived

Perceived

Sum of diffs

safety disorder (abs values)

$-0.137$

0.492

$-0.048$

$-0.148$

0.456

$-0.031$

0.06

$-0.136$

0.544

$-0.065$

0.07

$-0.080$

0.500

$-0.041$

0.07

$-0.181$

0.341

$-0.052$

0.20 


\section{Effectiveness}

The best in terms of analysis are:

- eff3 Responding quickly to calls for assistance?

- eff1 Resolving crimes where violence is involved?

CFA from 6 factor solution [STDYX]

eff3 Responding quickly to calls for assistance?

eff2 Resolving property crimes, such as theft?

CFA substitutability analysis [STDYX]

Base- 
$\begin{array}{ll}\text { Public Safety } & \text { Sécurité publique } \\ \text { Canada } & \text { Canada }\end{array}$

$$
\text { Canada }
$$

Demographic substitutability analysis

line

Demographics predicting effectiveness

eff 1

Resolving crimes where violence is involved?

eff2

Resolving property crimes, such as theft?

eff 3

Responding quickly to calls for assistance?

Base-

line

eff 3

eff 1

Responding quickly to calls for assistance?

Resolving crimes where violence is involved?

Resolving property crimes, such as theft?

\begin{tabular}{|c|c|c|c|c|c|c|c|}
\hline Age & Female & Income & White & $\begin{array}{l}\text { South } \\
\text { Asian }\end{array}$ & Chinese & Black & $\begin{array}{c}\text { Sum of } \\
\text { diffs } \\
\text { (abs } \\
\text { values) }\end{array}$ \\
\hline 0.004 & 0.068 & -0.001 & 0.052 & 0.402 & -0.108 & -0.145 & \\
\hline 0.003 & -0.022 & 0.018 & 0.103 & 0.149 & -0.121 & -0.262 & 0.68 \\
\hline 0.003 & 0.122 & -0.030 & -0.007 & 0.619 & -0.025 & 0.033 & 0.84 \\
\hline 0.004 & 0.094 & 0.009 & 0.044 & 0.436 & -0.171 & -0.154 & 0.91 \\
\hline Victim & $\begin{array}{c}\text { Perceived } \\
\text { safety }\end{array}$ & $\begin{array}{l}\text { Perceived } \\
\text { disorder }\end{array}$ & $\begin{array}{l}\text { Sum } \\
\text { labs }\end{array}$ & $\begin{array}{l}\text { of diffs } \\
\text { values) }\end{array}$ & & & \\
\hline-0.151 & 0.463 & -0.058 & & & & & \\
\hline-0.050 & 0.489 & -0.051 & & 0.13 & & & \\
\hline-0.002 & 0.445 & -0.051 & & 0.17 & & & \\
\hline-0.364 & 0.354 & -0.063 & & 0.33 & & & \\
\hline
\end{tabular}




\section{Legitimacy}

Theoretical priority: appropriateness and entitlement.

The following duty to obey indicator:

- obey I feel a moral duty to follow police orders.

The best in terms of analysis are:

- na2 I generally support how the police usually act.

CFA from 6 factor solution [STDYX]

na2 I generally support how the police usually act. 0.923

nal The police generally have the same sense of right and wrong as I do. 0.853

obey I feel a moral duty to follow police orders.

CFA substitutability analysis [STDYX]

Base-

Legitimacy predicting cooperation (no other predictors)

na2 I generally support how the police usually act.

nal The police generally have the same sense of right and wrong as I do.

obey I feel a moral duty to follow police orders. 
$\begin{array}{ll}\text { Public Safety } & \text { Sécurité publique } \\ \text { Canada } & \text { Canada }\end{array}$

$$
\begin{aligned}
& \text { Sécurité pub } \\
& \text { Canada }
\end{aligned}
$$

Demographic substitutability analysis

Demographics predicting legitimacy

obey I feel a moral duty to follow police orders.

na2 I generally support how the police usually act.

nal The police generally have the same sense of right and wrong as I do.

Base-

line

Demographics predicting legitimacy

nal The police generally have the same sense of right and wrong as I do.

na2 I generally support how the police usually act.

obey I feel a moral duty to follow police orders.

$\begin{array}{cccccccc}\text { Age } & \text { Female } & \text { Income } & \text { White } & \begin{array}{c}\text { South } \\ \text { Asian }\end{array} & \text { Chinese } & \text { Black } & \begin{array}{c}\text { Sum of } \\ \text { diffs } \\ \text { (abs } \\ \text { values) }\end{array} \\ 0.009 & 0.123 & 0.061 & 0.173 & 0.642 & 0.042 & -0.266 & \\ 0.006 & 0.243 & 0.057 & 0.202 & 0.619 & -0.022 & 0.080 & 1.23 \\ 0.011 & 0.073 & 0.063 & 0.182 & 0.689 & 0.069 & -0.323 & 1.41 \\ 0.009 & 0.072 & 0.063 & 0.139 & 0.609 & 0.088 & -0.483 & 1.46\end{array}$

Perceived

disorder

Sum of diffs

(abs values)

$-0.109 \quad 0.382$

$-0.069$

$-0.127$

$-0.081$

0.413

$-0.084$

0.06

0.449

$-0.067$

0.10

$-0.145$

0.255

$-0.058$

0.17 


\section{Cooperation}

The best in terms of analysis are:

- coop2 I would call the police for assistance.

- coop1 I would help the police if asked.

CFA from 6 factor solution [STDYX]

$\begin{array}{llr}\text { coop1 } & \text { I would help the police if asked. } & 0.922 \\ \text { coop2 } & \text { I would call the police for assistance. } & 0.908 \\ \text { coop3 } & \text { I would call the police to report a crime. } & 0.887 \\ \text { coop5 } & \text { I would help the police by giving evidence in court. } & 0.836 \\ \text { coop4 } & \text { I would report suspicious activities to police. } & 0.830\end{array}$

CFA substitutability analysis [STDYX]

$\begin{array}{lll}\begin{array}{l}\text { Base- } \\ \text { line }\end{array} & \text { Procedural justice predicting legitimacy (no other predictors) } & 0.791 \\ & & 0.609 \\ \text { coop1 I would help the police if asked. } & 0.579 \\ \text { coop2 I would call the police for assistance. } & 0.531 \\ \text { coop5 I would help the police by giving evidence in court. } & 0.524 \\ \text { coop3 I would call the police to report a crime. } & 0.507 \\ \text { coop4 I would report suspicious activities to police. }\end{array}$ 
Public Safety Sécurité publique
Canada

Demographic substitutability analysis

Demographics predicting cooperation

coop4 I would report suspicious activities to police.

coopl I would help the police if asked.

coop5 I would help the police by giving evidence in court.

coop3 I would call the police to report a crime.

coop2 I would call the police for assistance.

Base-

line

Demographics predicting cooperation

coop3 I would call the police to report a crime.

coopl I would help the police if asked.

coop5 I would help the police by giving evidence in court.

coop4 I would report suspicious activities to police.

coop2 I would call the police for assistance.

$\begin{array}{cccccccc}\text { Age } & \text { Female } & \text { Income } & \text { White } & \begin{array}{c}\text { South } \\ \text { Asian }\end{array} & \text { Chinese } & \text { Black } & \begin{array}{c}\text { Sum of } \\ \text { diffs } \\ \text { (abs } \\ \text { values) }\end{array} \\ 0.013 & 0.226 & 0.096 & 0.136 & 0.503 & -0.266 & -0.195 & \\ 0.016 & 0.257 & 0.086 & 0.152 & 0.554 & -0.125 & 0.001 & 1.19 \\ 0.009 & 0.160 & 0.096 & 0.148 & 0.629 & -0.147 & -0.179 & 1.37 \\ 0.012 & 0.159 & 0.095 & 0.015 & 0.462 & -0.165 & -0.460 & 1.37 \\ 0.013 & 0.226 & 0.107 & 0.132 & 0.455 & -0.487 & -0.099 & 1.52 \\ 0.011 & 0.303 & 0.080 & 0.216 & 0.347 & -0.365 & -0.220 & 1.54\end{array}$

Victim Perceived safety

Perceived disorder

Sum of diffs (abs

$0.282 \quad-0.040$ values)

$-0.107$

0.024

0.022

0.027

0.07

$-0.050$

$-0.022$

$-0.020$

0.09

$-0.073$

0.001

$-0.027$

0.10

$\begin{array}{ll}-0.018 & 0.069\end{array}$

$-0.014$

0.10

$\begin{array}{lll}0.086 & -0.029 & 0.029\end{array}$

0.14 


\section{Appendix B: Survey Instrument}

Thank you for taking the time to participate in this survey. It should take approximately 10 minutes or so to complete. Please answer all questions honestly and try to provide a response to all questions. All of your responses are collected anonymously. If you don't know how to answer any specific question, please leave that question blank and move on to the next question. Your participation is voluntary and your responses will be kept entirely confidential and anonymous, and will be used solely for research purposes. Thank you for your time and assistance.

1. Of the languages you understand, which one did you learn first?

English $\mathrm{O}_{1}$

French $\mathrm{O}_{2}$

Other $\mathrm{O}_{3}$

2. [ASK IF FRENCH IN Q.1] We would appreciate receiving your survey responses in French, if that is acceptable to you. Would you complete the survey in French?

Yes $\mathrm{O}_{1}$ - CONTINUE IN FRENCH

No $\mathrm{O}_{2}-$ CONTINUE IN ENGLISH

3. [ASK IF ENGLISH OR OTHER IN Q.1] Would you like to complete the survey in English or French?

English $\mathrm{O}_{1}$

French $\mathrm{O}_{2}$

4. In which province or territory do you live?

Alberta $\mathrm{O}_{1}$

British Columbia $\mathrm{O}_{2}$

Manitoba $\mathrm{O}_{3}$

New Brunswick $\mathrm{O}_{4}$

Newfoundland and Labrador $\mathrm{O}_{5}$

Nova Scotia $\mathrm{O}_{6}$

Ontario $\bigcirc \quad 7$

Prince Edward Island $\bigcirc \quad 8$

Quebec $\bigcirc$,

Saskatchewan $\mathrm{O}_{10}$

Northwest Territories $\mathrm{O}_{11}$

Nunavut $\mathrm{O}_{12}$

Yukon $\bigcirc \quad 13$

Outside of Canada $\bigcirc \quad$ 14 TERMINATE

5. [IF ALBERTA IN Q.4] Do you live within the city of Calgary?

Yes $\mathrm{O}_{1}$ -

$\mathrm{NoO}_{2}$

6. [IF NOVA SCOTIA IN Q.4] Do you live within the Halifax Regional Municipality?

Yes $\mathrm{O}_{1}$

$\mathrm{NoO}_{2}$

6b. [IF ONTARIO IN Q.4] Do you live within the city of Ottawa?

Yes $\mathrm{O}_{1}$ -

$\mathrm{NoO}_{2}$

7. What are the first three digits of your postal code?

8. [table linking responses to the above questions to quota requirements and respondent inclusion/exclusion criteria] 
9. What is your age? (in years)

10. What is your gender?

Male $\mathrm{O}_{1}$

Female $\mathrm{O}_{2}$

Non-binary $\mathrm{O}_{3}$

Prefer not to answer $\mathrm{O}_{7}$

11. To which of the following racial or cultural groups do you belong? Please select all that apply. White $\mathrm{O}_{1}$

South Asian (e.g., East Indian, Pakistani, Sri Lankan, etc.) $\mathrm{O}_{2}$

Chinese $\mathrm{O}_{3}$

Black $\mathrm{O}_{4}$

Filipino $\mathrm{O}_{5}$

Latin American $\mathrm{O}_{6}$

Arab $\mathrm{O}_{7}$

Southeast Asian (e.g., Vietnamese, Cambodian, Laotian, Thai, etc.) $\mathrm{O}_{8}$

West Asian (e.g., Iranian, Afghan, etc.) $O_{9}$

Korean $\mathrm{O}_{10}$

Japanese $\mathrm{O}_{11}$

First Nations (North American Indian; includes Status and Non-Status Indians) $\mathrm{O}_{12}$

Métis $\mathrm{O}_{13}$

Inuk (Inuit) $\bigcirc_{14}$

Other $\mathrm{O}_{15}$

(Refused) $\bigcirc_{97}$

12. Which of the following categories best describes your total household income in 2017? That is, the total income of all persons in your household combined, before taxes?

Under $\$ 20,000 O_{1}$

$\$ 20,000$ to just under $\$ 40,000 \mathrm{O}_{2}$

$\$ 40,000$ to just under $\$ 60,000 \mathrm{O}_{3}$

$\$ 60,000$ to just under $\$ 80,000 \mathrm{O}_{4}$

$\$ 80,000$ to just under $\$ 100,000 \bigcirc_{5}$

$\$ 100,000$ to just under $\$ 150,000 \bigcirc_{6}$

$\$ 150,000$ or above $\mathrm{O}_{7}$

Prefer not to answer $\mathrm{O}_{9}$

13. When you think about [INSERT POLICE SERVICE], to what extent do you agree or disagree with each of the following statements?

\begin{tabular}{|c|c|c|c|c|c|}
\hline Item & $\begin{array}{l}\text { Strongly } \\
\text { Disagree }\end{array}$ & Disagree & $\begin{array}{c}\text { Neither } \\
\text { agree } \\
\text { nor } \\
\text { disagree }\end{array}$ & Agree & $\begin{array}{l}\text { Strongly } \\
\text { Agree }\end{array}$ \\
\hline a. The police treat people fairly (Procedural Justice - Block 1) & $\mathrm{O}_{1}$ & $\mathrm{O}_{2}$ & $\mathrm{O}_{3}$ & $\mathrm{O}_{4}$ & $\mathrm{O}_{5}$ \\
\hline $\begin{array}{l}\text { b. The police treat people with respect (Procedural Justice - } \\
\text { Block 1) }\end{array}$ & $\mathrm{O}_{1}$ & $\mathrm{O}_{2}$ & $\mathrm{O}_{3}$ & $\mathrm{O}_{4}$ & $\mathrm{O}_{5}$ \\
\hline $\begin{array}{l}\text { c. The police make decisions based on facts } \\
\text { (Procedural Justice - Block 1) }\end{array}$ & $\mathrm{O}_{1}$ & $\mathrm{O}_{2}$ & $\mathrm{O}_{3}$ & $\mathrm{O}_{4}$ & $\mathrm{O}_{5}$ \\
\hline d. The police respect people's rights (Procedural Justice - Block & $\mathrm{O}_{1}$ & $\mathrm{O}_{2}$ & $\mathrm{O}_{3}$ & $\mathrm{O}_{4}$ & $\mathrm{O}_{5}$ \\
\hline
\end{tabular}




\begin{tabular}{|c|c|c|c|c|c|}
\hline 1) & & & & & \\
\hline $\begin{array}{l}\text { e. The police address citizens in a respectful manner and } \\
\text { appropriate tone (Procedural Justice- Block } 1 \text { ) }\end{array}$ & $\mathrm{O}_{1}$ & $\mathrm{O}_{2}$ & $\mathrm{O}_{3}$ & $\bigcirc_{4}$ & $\mathrm{O}_{5}$ \\
\hline $\begin{array}{l}\text { f. The police show care and concern for the welfare of the } \\
\text { citizens they deal with (Procedural Justice- Block 1) }\end{array}$ & $\mathrm{O}_{1}$ & $\mathrm{O}_{2}$ & $\mathrm{O}_{3}$ & $\mathrm{O}_{4}$ & $\mathrm{O}_{5}$ \\
\hline $\begin{array}{l}\text { g. The police know how to carry out their official duties properly } \\
\text { (Procedural Justice - Block 1) }\end{array}$ & $\mathrm{O}_{1}$ & $\mathrm{O}_{2}$ & $\mathrm{O}_{3}$ & $\mathrm{O}_{4}$ & $\bigcirc_{5}$ \\
\hline $\begin{array}{l}\text { h. The police treat you with respect if you had contact with them } \\
\text { for any reason (Procedural Justice - Block 1) }\end{array}$ & $\mathrm{O}_{1}$ & $\mathrm{O}_{2}$ & $\mathrm{O}_{3}$ & $\mathrm{O}_{4}$ & $\mathrm{O}_{5}$ \\
\hline $\begin{array}{l}\text { i. The police explain their decisions to the people they deal with } \\
\text { (Procedural Justice - Block 1) }\end{array}$ & $\mathrm{O}_{1}$ & $\mathrm{O}_{2}$ & $\mathrm{O}_{3}$ & $\mathrm{O}_{4}$ & $\bigcirc_{5}$ \\
\hline $\begin{array}{l}\text { j. The [INSERT POLICE SERVICE] [is/are] an organization with } \\
\text { integrity (Procedural Justice - Block 1) }\end{array}$ & $\mathrm{O}_{1}$ & $\mathrm{O}_{2}$ & $\mathrm{O}_{3}$ & $\mathrm{O}_{4}$ & $\mathrm{O}_{5}$ \\
\hline $\begin{array}{l}\text { k. The [INSERT POLICE SERVICE] [is/are] an open and } \\
\text { transparent organization (Procedural Justice - Block 1) }\end{array}$ & $\mathrm{O}_{1}$ & $\mathrm{O}_{2}$ & $\mathrm{O}_{3}$ & $\mathrm{O}_{4}$ & $\mathrm{O}_{5}$ \\
\hline $\begin{array}{l}\text { I. The police treat everyone fairly, regardless of who they are } \\
\text { (Distributive Justice - Block 2) }\end{array}$ & $\mathrm{O}_{1}$ & $\mathrm{O}_{2}$ & $\mathrm{O}_{3}$ & $\bigcirc_{4}$ & $\bigcirc_{5}$ \\
\hline $\begin{array}{l}\text { m. The police treat everyone equally (Distributive Justice - } \\
\text { Block 2) }\end{array}$ & $\mathrm{O}_{1}$ & $\mathrm{O}_{2}$ & $\mathrm{O}_{3}$ & $\mathrm{O}_{4}$ & $\bigcirc_{5}$ \\
\hline $\begin{array}{l}\text { n. The police provide the same quality of service to all citizens } \\
\text { (Distributive Justice - Block 2) }\end{array}$ & $\mathrm{O}_{1}$ & $\mathrm{O}_{2}$ & $\mathrm{O}_{3}$ & $\mathrm{O}_{4}$ & $\mathrm{O}_{5}$ \\
\hline $\begin{array}{l}\text { o. The police enforce the law consistently when dealing with } \\
\text { people (Distributive Justice - Block 2) }\end{array}$ & $\mathrm{O}_{1}$ & $\mathrm{O}_{2}$ & $\mathrm{O}_{3}$ & $\mathrm{O}_{4}$ & $\mathrm{O}_{5}$ \\
\hline $\begin{array}{l}\text { p. The police understand the issues that affect this community } \\
\text { (Community Engagement - Block } 3 \text { ) }\end{array}$ & $\mathrm{O}_{1}$ & $\mathrm{O}_{2}$ & $\mathrm{O}_{3}$ & $\mathrm{O}_{4}$ & $\mathrm{O}_{5}$ \\
\hline $\begin{array}{l}\text { q. The police are dealing with the things that matter to people in } \\
\text { this community (Community Engagement - Block } 3 \text { ) }\end{array}$ & $\mathrm{O}_{1}$ & $\mathrm{O}_{2}$ & $\mathrm{O}_{3}$ & $\mathrm{O}_{4}$ & $\mathrm{O}_{5}$ \\
\hline $\begin{array}{l}\text { r. The police can be relied on to be there when you need them } \\
\text { (Community Engagement - Block } \mathbf{3} \text { ) }\end{array}$ & $\mathrm{O}_{1}$ & $\mathrm{O}_{2}$ & $\mathrm{O}_{3}$ & $\mathrm{O}_{4}$ & $\mathrm{O}_{5}$ \\
\hline $\begin{array}{l}\text { s. The police are sensitive to the needs of different cultures } \\
\text { (Community Engagement - Block } 3 \text { ) }\end{array}$ & $\mathrm{O}_{1}$ & $\mathrm{O}_{2}$ & $\mathrm{O}_{3}$ & $\mathrm{O}_{4}$ & $\bigcirc_{5}$ \\
\hline $\begin{array}{l}\text { t. The police generally have the same sense of right and wrong } \\
\text { as I do (Legitimacy - Block 4) }\end{array}$ & $\mathrm{O}_{1}$ & $\mathrm{O}_{2}$ & $\mathrm{O}_{3}$ & $\mathrm{O}_{4}$ & $\mathrm{O}_{5}$ \\
\hline $\begin{array}{l}\text { u. I generally support how the police usually act (Legitimacy - } \\
\text { Block 4) }\end{array}$ & $\mathrm{O}_{1}$ & $\mathrm{O}_{2}$ & $\mathrm{O}_{3}$ & $\mathrm{O}_{4}$ & $\mathrm{O}_{5}$ \\
\hline $\begin{array}{l}\text { v. I feel a moral duty to follow police orders (Legitimacy - Block } \\
\text { 4) }\end{array}$ & $\mathrm{O}_{1}$ & $\mathrm{O}_{2}$ & $\mathrm{O}_{3}$ & $\mathrm{O}_{4}$ & $\mathrm{O}_{5}$ \\
\hline w. I would help the police if asked (Cooperation - Block 5) & $\mathrm{O}_{1}$ & $\mathrm{O}_{2}$ & $\mathrm{O}_{3}$ & $\mathrm{O}_{4}$ & $\mathrm{O}_{5}$ \\
\hline x. I would call the police for assistance (Cooperation - Block 5) & $\mathrm{O}_{1}$ & $\mathrm{O}_{2}$ & $\mathrm{O}_{3}$ & $\mathrm{O}_{4}$ & $\mathrm{O}_{5}$ \\
\hline $\begin{array}{l}\text { y. I would call the police to report a crime } \\
\text { (Legitimacy/Cooperation - Block 5) }\end{array}$ & $\mathrm{O}_{1}$ & $\mathrm{O}_{2}$ & $\mathrm{O}_{3}$ & $\mathrm{O}_{4}$ & $\mathrm{O}_{5}$ \\
\hline $\begin{array}{l}\text { z. I would report suspicious activities to police (Cooperation - } \\
\text { Block 5) }\end{array}$ & $\mathrm{O}_{1}$ & $\mathrm{O}_{2}$ & $\mathrm{O}_{3}$ & $\mathrm{O}_{4}$ & $\mathrm{O}_{5}$ \\
\hline $\begin{array}{l}\text { aa. I would help the police by giving evidence in court } \\
\text { (Cooperation - Block 5) }\end{array}$ & $\mathrm{O}_{1}$ & $\mathrm{O}_{2}$ & $\mathrm{O}_{3}$ & $\mathrm{O}_{4}$ & $\mathrm{O}_{5}$ \\
\hline
\end{tabular}


14. How often would you say that the police in your neighbourhood make fair, impartial decisions in the cases they deal with?

Never/Almost never $\mathrm{O}_{1}$

Rarely $\mathrm{O}_{2}$

Sometimes $\mathrm{O}_{3}$

Most of the time $\mathrm{O}_{4}$

Always/Almost always $\mathrm{O}_{5}$

15. About how often would you say that the police in your neighbourhood exceed their authority? Never/Almost never $\mathrm{O}_{1}$

Rarely $\mathrm{O}_{2}$

Sometimes $\mathrm{O}_{3}$

Most of the time $\mathrm{O}_{4}$

Always/Almost always $\mathrm{O}_{5}$

16. In general, to what extent do you agree that the [INSERT POLICE SERVICE] [is/are] effective at ...: ROTATE LIST

\begin{tabular}{|l|c|c|c|c|c|}
\hline Item & $\begin{array}{c}\text { Strongly } \\
\text { Disagree }\end{array}$ & Disagree & $\begin{array}{c}\text { Neither } \\
\text { agree } \\
\text { nor } \\
\text { disagree }\end{array}$ & $\begin{array}{c}\text { Agree } \\
\text { Agree }\end{array}$ \\
\hline a. Resolving crimes when violence is involved? & $\mathrm{O}_{1}$ & $\mathrm{O}_{2}$ & $\mathrm{O}_{3}$ & $\mathrm{O}_{4}$ & $\mathrm{O}_{5}$ \\
\hline b. Resolving property crimes, such as theft? & $\mathrm{O}_{1}$ & $\mathrm{O}_{2}$ & $\mathrm{O}_{3}$ & $\mathrm{O}_{4}$ & $\mathrm{O}_{5}$ \\
\hline c. Responding quickly to calls for assistance? & $\mathrm{O}_{1}$ & $\mathrm{O}_{2}$ & $\mathrm{O}_{3}$ & $\mathrm{O}_{4}$ & $\mathrm{O}_{5}$ \\
\hline
\end{tabular}

17. Overall, how would you rate your satisfaction with the [INSERT POLICE SERVICE]?

Very dissatisfied $\mathrm{O}_{1}$

Dissatisfied $\mathrm{O}_{2}$

Neither satisfied nor dissatisfied $\mathrm{O}_{3}$

Satisfied $\mathrm{O}_{4}$

Very satisfied $\mathrm{O}_{5}$

18. In the past 2 years, did the police approach you, stop you or make contact with you for any reason?

Yes $\mathrm{O}_{1}$

$\mathrm{No} \mathrm{O}_{2}$

19. [ASK IF YES IN Q.18] How dissatisfied or satisfied were you with the way the police treated you the last time this happened?

Very dissatisfied $\mathrm{O}_{1}$

Dissatisfied $\mathrm{O}_{2}$

Neither satisfied nor dissatisfied $\mathrm{O}_{3}$

Satisfied $\mathrm{O}_{4}$

Very satisfied $\mathrm{O}_{5}$

20. In the past 2 years, have you approached or contacted the police for any reason?

Yes $\mathrm{O}_{1}$

No $\mathrm{O}_{2}$ 
21. [ASK IF YES IN Q.20] How dissatisfied or satisfied were you with the way the police treated you the last time this happened?

Very dissatisfied $\mathrm{O}_{1}$

Dissatisfied $\mathrm{O}_{2}$

Neither satisfied nor dissatisfied $\mathrm{O}_{3}$

Satisfied $\mathrm{O}_{4}$

Very satisfied $\mathrm{O}_{5}$

22. Approximately how many times have you had contact of any sort with police in the past two years?

23. Approximately how many times have you been stopped and questioned by the police in the past two years, including times that you were driving a vehicle or walking or hanging out in public?

24. [ASK IF 1 OR MORE IN Q.22 AND/OR Q.23] Based on your interactions with your local police in the past 2 years, to what degree were your local police:

\begin{tabular}{|c|c|c|c|c|c|}
\hline \multirow[t]{2}{*}{ a. Helpful when you asked them for assistance } & $\begin{array}{c}\text { Very } \\
\text { Unhelpful }\end{array}$ & Unhelpful & $\begin{array}{l}\text { Neither } \\
\text { Helpful } \\
\text { nor } \\
\text { Unhelpful }\end{array}$ & Helpful & $\begin{array}{l}\text { Very } \\
\text { Helpful }\end{array}$ \\
\hline & $\mathrm{O}_{1}$ & $\mathrm{O}_{2}$ & $\mathrm{O}_{3}$ & $\mathrm{O}_{4}$ & $\mathrm{O}_{5}$ \\
\hline \multirow[t]{2}{*}{ b. Polite to you } & $\begin{array}{c}\text { Very } \\
\text { Impolite }\end{array}$ & Impolite & $\begin{array}{l}\text { Neither } \\
\text { Polite nor } \\
\text { Impolite }\end{array}$ & Polite & $\begin{array}{l}\text { Very } \\
\text { Polite }\end{array}$ \\
\hline & $\mathrm{O}_{1}$ & $\mathrm{O}_{2}$ & $\mathrm{O}_{3}$ & $\mathrm{O}_{4}$ & $\mathrm{O}_{5}$ \\
\hline \multirow[t]{2}{*}{ c. Fair during your interactions } & $\begin{array}{l}\text { Very } \\
\text { Unfair }\end{array}$ & Unfair & $\begin{array}{l}\text { Neither } \\
\text { Fair nor } \\
\text { Unfair }\end{array}$ & Fair & $\begin{array}{l}\text { Very } \\
\text { Fair }\end{array}$ \\
\hline & $\mathrm{O}_{1}$ & $\mathrm{O}_{2}$ & $\mathrm{O}_{3}$ & $\mathrm{O}_{4}$ & $\mathrm{O}_{5}$ \\
\hline
\end{tabular}

25. In the past two years, have you been a victim of any crime?

Yes $\mathrm{O}_{1}$

$\mathrm{NoO}_{2}$

26. [ASK IF YES IN Q.25] Did you report the crime to the police on any of the occasions that you were victimized in the past two years?

Yes $\mathrm{O}_{1}$

$\mathrm{No} \mathrm{O}_{2}$

27. [ASK IF YES IN Q.25] How dissatisfied or satisfied were you with the way the police treated you the last time this happened?

Very dissatisfied $\mathrm{O}_{1}$

Dissatisfied $\mathrm{O}_{2}$

Neither satisfied nor dissatisfied $\mathrm{O}_{3}$

Satisfied $\mathrm{O}_{4}$

Very satisfied $\mathrm{O}_{5}$

I have not had contact with the police after my victimization in the past 2 years $\mathrm{O}_{6}$ 
28. In general, how satisfied are you with your personal safety from crime?

Very dissatisfied $\mathrm{O}_{1}$

Dissatisfied $\mathrm{O}_{2}$

Neither satisfied nor dissatisfied $\mathrm{O}_{3}$

Satisfied $\mathrm{O}_{4}$

Very satisfied $\mathrm{O}_{5}$

29. How safe do you feel from crime walking alone in your area after dark? Do you feel ...?

Very safe $\mathrm{O}_{1}$

Reasonably safe $\mathrm{O}_{2}$

Somewhat unsafe $\mathrm{O}_{3}$

Very unsafe $\mathrm{O}_{4}$

Do not walk alone $\mathrm{O}_{5}$

30. During the last 5 years, do you think that crime in your neighbourhood has ...?

Increased $\mathrm{O}_{1}$

Stayed the same $\mathrm{O}_{2}$

Decreased $\mathrm{O}_{3}$

Just moved into the area/

Have not lived in neighbourhood long enough $\mathrm{O}_{4}$

31. In your neighbourhood, how much of a problem are:

\begin{tabular}{|l|c|c|c|c|}
\hline Item & $\begin{array}{c}\text { A big } \\
\text { problem }\end{array}$ & $\begin{array}{c}\text { A } \\
\text { moderate } \\
\text { problem }\end{array}$ & $\begin{array}{c}\text { A small } \\
\text { problem }\end{array}$ & $\begin{array}{c}\text { Not a } \\
\text { problem } \\
\text { at all }\end{array}$ \\
\hline a. Noisy neighbours or loud parties? & $\mathrm{O}_{1}$ & $\mathrm{O}_{2}$ & $\mathrm{O}_{3}$ & $\mathrm{O}_{4}$ \\
\hline b. People hanging around on the streets? & $\mathrm{O}_{1}$ & $\mathrm{O}_{2}$ & $\mathrm{O}_{3}$ & $\mathrm{O}_{4}$ \\
\hline c. Garbage or litter lying around? & $\mathrm{O}_{1}$ & $\mathrm{O}_{2}$ & $\mathrm{O}_{3}$ & $\mathrm{O}_{4}$ \\
\hline $\begin{array}{l}\text { d. Vandalism, graffiti and other deliberate damage to property or } \\
\text { vehicles? }\end{array}$ & $\mathrm{O}_{1}$ & $\mathrm{O}_{2}$ & $\mathrm{O}_{3}$ & $\mathrm{O}_{4}$ \\
\hline $\begin{array}{l}\text { e. People being attacked or harassed because of their skin colour, } \\
\text { ethnic origin or religion? }\end{array}$ & $\mathrm{O}_{1}$ & $\mathrm{O}_{2}$ & $\mathrm{O}_{3}$ & $\mathrm{O}_{4}$ \\
\hline $\begin{array}{l}\text { f. People using or dealing drugs? } \\
\text { g. People being drunk or rowdy in public places? }\end{array} \mathrm{O}_{1}$ & $\mathrm{O}_{2}$ & $\mathrm{O}_{3}$ & $\mathrm{O}_{4}$ \\
\hline
\end{tabular}

32. How much confidence do you have in the police?

A great deal of confidence $\mathrm{O}_{1}$

Some confidence $\mathrm{O}_{2}$

Not very much confidence $\mathrm{O}_{3}$

No confidence at all $\mathrm{O}_{4}$ 
33. Taking everything into account, how good a job do you think the police in this area are doing? Very poor $\mathrm{O}_{1}$

Poor $\mathrm{O}_{2}$

Average $\mathrm{O}_{3}$

Good $\mathrm{O}_{4}$

Excellent $\mathrm{O}_{5}$

34. Taking everything into account, how good a job do you think the police in this country are doing? Very poor $\mathrm{O}_{1}$

Poor $\mathrm{O}_{2}$

Average $\mathrm{O}_{3}$

Good $\mathrm{O}_{4}$

Excellent $\mathrm{O}_{5}$

[END OF DOCUMENT] 